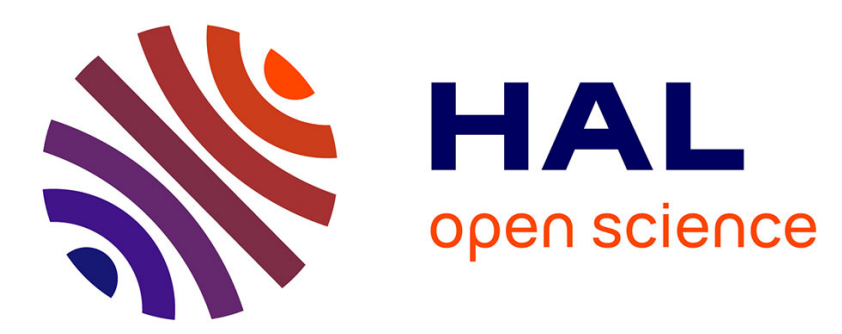

\title{
Fatigue behaviour of additively manufactured Ti-6Al-4V alloy: The role of defects on scatter and statistical size effect
}

\author{
Viet-Duc Le, Etienne Pessard, Franck Morel, Serge Prigent
}

\section{To cite this version:}

Viet-Duc Le, Etienne Pessard, Franck Morel, Serge Prigent. Fatigue behaviour of additively manufactured Ti-6Al-4V alloy: The role of defects on scatter and statistical size effect. International Journal of Fatigue, 2020, 140, pp.105811. 10.1016/j.ijfatigue.2020.105811 . hal-02969486

\section{HAL Id: hal-02969486 \\ https://hal.science/hal-02969486}

Submitted on 16 Oct 2020

HAL is a multi-disciplinary open access archive for the deposit and dissemination of scientific research documents, whether they are published or not. The documents may come from teaching and research institutions in France or abroad, or from public or private research centers.
L'archive ouverte pluridisciplinaire HAL, est destinée au dépôt et à la diffusion de documents scientifiques de niveau recherche, publiés ou non, émanant des établissements d'enseignement et de recherche français ou étrangers, des laboratoires publics ou privés. 


\title{
Fatigue behaviour of Additively Manufactured Ti-6Al-4V alloy : the role of defects on scatter and statistical size effect
}

\author{
Viet-Duc LE ${ }^{\mathrm{a}, *}$, Etienne PESSARD ${ }^{\mathrm{a}}$, Franck MOREL ${ }^{\mathrm{a}}$, Serge PRIGENT ${ }^{\mathrm{b}}$ \\ ${ }^{a}$ Arts et Metiers Institute of Technology, LAMPA, HESAM Université, Address :F-49035 Angers, FRANCE \\ ${ }^{b}$ IRT Jules Verne, 44340-Bouguenais, FRANCE
}

\begin{abstract}
This work is focused on the influence of defects on scatter and statistical size effect of Ti-6Al-4V alloy fabricated by the SLM process. A vast fatigue test campaign has been undertaken, for two surface conditions (as-built and machined surfaces) and two specimen geometries with different highly loaded volume sizes. It was shown, for machined specimens, that a large variety of crack initiation mechanisms is the principal origin of the fatigue scatter. Regarding the size effect, the change of the mechanism is the first order factor that governs the size effect. For as-built specimens, these effects are much less pronounced.
\end{abstract}

Keywords: Fatigue behaviour; Additive manufacturing; Ti-6Al-4V; porosity; size effect

\section{Introduction}

For most metallic materials, the microstructure, microstructural defects and surface roughness are the fingerprints for the prediction of their macroscopic mechanical behaviour. For the case of 4 Selective Laser Melting (SLM) of metal Additive Manufacturing (AM), the precise control of the 5 microstructure, porosity (i.e. gas and Lack-of-Fusion (LoF) pores) and surface roughness is not the two main defect types found in SLM additively manufactured Ti-6Al-4V alloys, porosity and

\footnotetext{
${ }^{*}$ Corresponding author: Viet-Duc LE

Email address: viet-duc. le@ensam.eu (Viet-Duc LE)
} 
surface roughness, on the fatigue behaviour in the high cycle fatigue regime. In the scientific literature, the effect of these factors on the fatigue strength has been investigated in numerous studies. Concerning the effect of the porosity, several studies have highlighted the effect of pore size on the fatigue behaviour of AM Ti-6Al-4V alloys [1-4]. In the work of Günther et al. [2], the authors showed the presence of different defect types from which the fatigue crack initiates such as LoF pores and gas pores or $\alpha$-phase. The same observations were made in the work of Chastand et al. [3] in which the authors observed several defect types such as surface defects, un-melted zones and small defects. In order to model the effect of these defects on the fatigue strength, linear elastic fracture mechanics based approaches have been widely used [5-7] and show globally satisfactory predictions. However, very little work clearly characterises the fatigue behaviour related to each defect type at the origin of the crack initiation sites.

Regarding the effect of the as built surface on the fatigue behaviour, numerous studies [8- -12 ] have shown that the as built surface is detrimental to the fatigue strength. Several approaches have been developed in the literature to model the effect of surface roughness defects. Vayssette el al. [8] tried to estimate the fatigue strength via numerical simulations by using the finite element method and achieved satisfactory predictions. In the work of Nakatani et al. [11], the classical Murakami approach is used in which the surface roughness defect size is measured by using the $\sqrt{\text { area }}$ parameter. However, it seems that this parameter alone is not adequate to achieve good results. In the work of Nasab et al. [10], the authors tried to describe the competition between crack initiation from surface pores and crack initiation from the surface roughness using a probabilistic approach. However, none of these studies investigated the difference in the fatigue strength between the as-built surface and a machined surface for the same crack initiation mechanism, in particular when initiation from surface pores is dominant.

Concerning the scale/size effect, it was shown in the studies of Pegue et al. [13] and Fatemi et al. [14] that the size effect on the fatigue behaviour for as-built surface specimens is not significant. The authors showed that the fatigue strength of as-built specimens does not change significantly when changing the gauge length and gauge diameter. For machined specimens, Fatemi et al. [14] showed that the size effect is more pronounced. However, few analyses of the critical defects were shown in these works to better understand the origin of the size effect. 
The objective of the present work is to characterise the fatigue behaviour, in particular the fatigue scatter and the size effect, of the Ti-6Al-4V alloy obtained by the SLM process. In order to achieve this aim, 4 specimen configurations were fabricated and investigated, corresponding to two surface conditions (as-built and machined surfaces) and to two specimen sizes (standard size and small size).

In the first part of this paper, the material properties including the microstructures, the surface roughness and the tensile properties are briefly presented, followed by the characterisation of the fatigue behaviour and associated damage mechanisms. It will be shown that numerous different fatigue crack initiation mechanisms are active. The critical defect size at the crack initiation sites are also characterised.

In the second part of the paper, the link between the fatigue behaviour and the crack initiation mechanisms is highlighted. The S-N curves are analysed separately for each damage mechanism. In order to take into account the pore size, a "corrected stress", introduced in one of the present authors previous publication [15], is used. A Kitagawa-Takahashi approach is also used to analyse the effect of pore size on the fatigue strength. A comparison of the fatigue behaviour between the machined and as-built surface, for the same fatigue damage mechanism, shows a pronounced effect of the as-built surface.

In the final part, the statistical size effect on the fatigue strength will be discussed by comparing the fatigue behaviour between the standard size and small size specimens. Finally, a probabilistic approach is proposed to describe the statistical size effect. The model predicts the probability of occurrence of the LoF pores, the most detrimental defect type, in a given volume.

\subsection{Specimen fabrication}

The titanium alloy used in this work is grade 23, Ti-6Al-4V ELI. The chemical composition is shown in Table 1 .

\begin{tabular}{|c|c|c|c|c|c|c|}
\hline $\mathrm{Al}$ & $\mathrm{V}$ & $\mathrm{C}$ & $\mathrm{Fe}$ & $\mathrm{H}$ & $\mathrm{N}$ & $\mathrm{O}$ \\
\hline 6.0 & 4.0 & $\leq 0.08$ & $\leq 0.25$ & $\leq 0.012$ & $\leq 0.05$ & $\leq 0.13$ \\
\hline
\end{tabular}

Table 1: Standardized chemical composition (in weight percentage) of the Ti-6Al-4V alloy[16] 

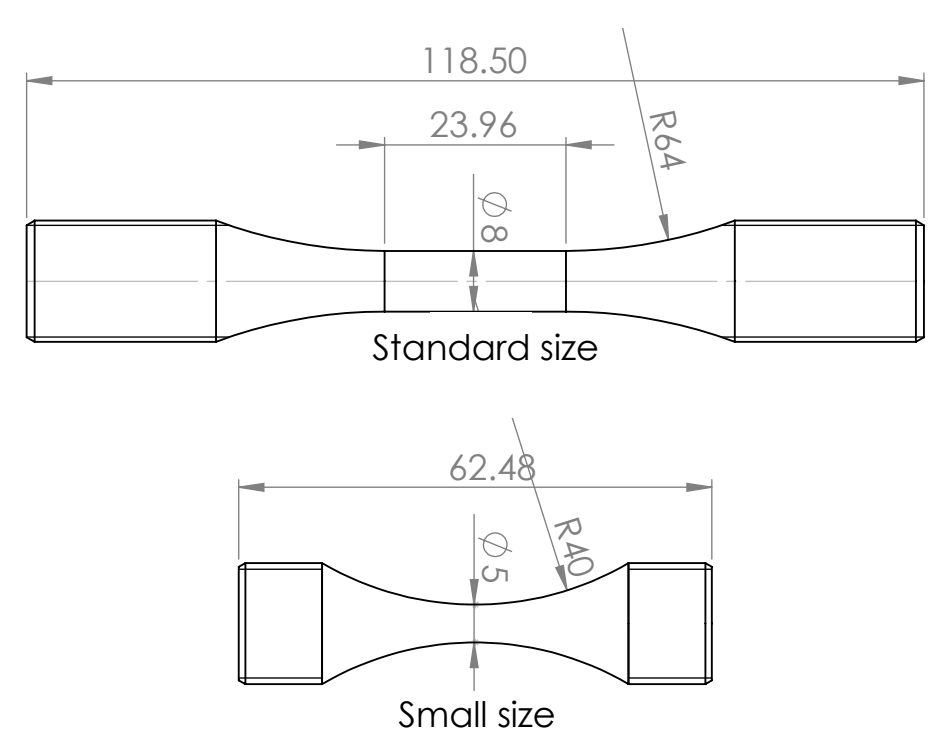

Small size

Figure 1: Two fatigue specimen geometries

The powder was supplied by AP\&C with a particle size range of $20 \mu \mathrm{m}-63 \mu \mathrm{m}$ with a median size of $43 \mu \mathrm{m}$. The specimens were manufactured by the Jules Verne Research and Technology Institute in France (IRT Jules Verne), using a SLM 280HL machine. The standard parameters recommended by the machine maker were used for the fabrication. In total, 68 fatigue specimens were fabricated, randomly mixed on 4 batches (two of them are shown in Figure 2).

In the previous work [15], several building directions $\left(0^{\circ}, 45^{\circ}, 90^{\circ}\right)$ were used in order to investigate the effect of this factor on the fatigue behaviour. In the present work, all of the specimens were fabricated vertically (i.e. the most critical building direction in relation to the fatigue strength) with two specimen geometries as shown in Figure 1 . The standard size geometry is proposed in the standard ISO - NF EN 6072 - June 2012 while the small size geometry was chosen so that the loaded volume is much smaller than the standard size geometry without introducing a strong stress concentration. For information, the $V_{80 \%}$ (highly loaded volume in which the lowest stress is equal to the $80 \%$ of the highest stress in the whole specimen) under uniaxial tensile loads corresponding to these two geometries are respectively $2044 \mathrm{~mm}^{3}$ and $206 \mathrm{~mm}^{3}$.

\footnotetext{
All of the as-fabricated specimens were post-heat treated by the following heat treatment (annealing at $850{ }^{\circ} \mathrm{C}$ for 2 hours followed by slow cooling within the furnace) to relax the residual stresses due to fabrication.
} 


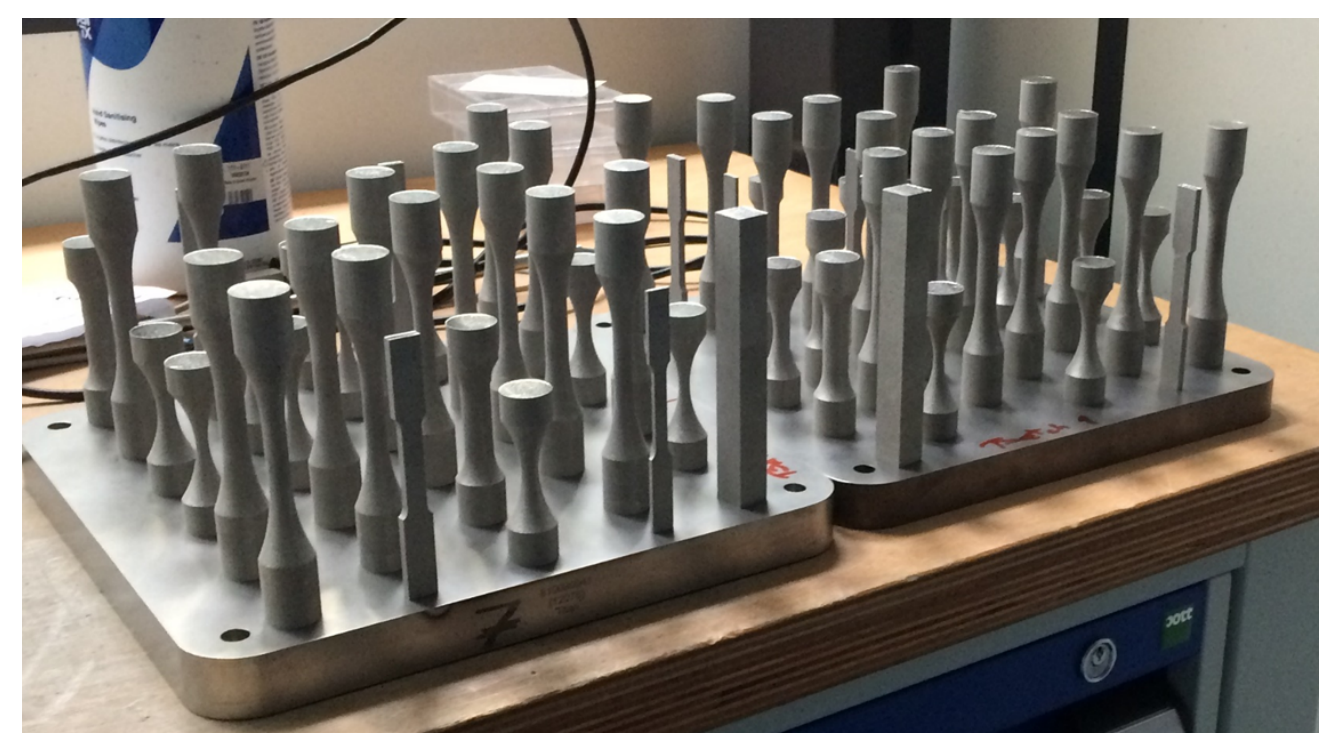

Figure 2: Two (in a total of four) fabricated batches of specimens

The machining was realised after the post-heat treatment. For the as-built surface specimens, only the threaded heads were machined while the calibrated zone was left as-fabricated with the diameters as indicated in Figure 1, i.e. $\Phi 8 \mathrm{~mm}$ for the standard size and $\Phi 5 \mathrm{~mm}$ for the small size. For the machined surface configurations, the as-fabricated gauge diameters were $\Phi 10 \mathrm{~mm}$ for standard size and $\Phi 7 \mathrm{~mm}$ for small size. After removing $1 \mathrm{~mm}$ from the radius by machining, the gauge diameters of the machined specimens are the same as the as-built specimens. Four specimen configurations and the associated number of specimen are given in Table 2.

\begin{tabular}{|c|c|}
\hline Configuration & Number of specimens \\
\hline Standard size - Machined & 20 \\
\hline Small size - Machined & 19 \\
\hline Standard size - As-built & 14 \\
\hline Small size - As-built & 15 \\
\hline
\end{tabular}

Table 2: Four specimen configurations and associated number of specimens 

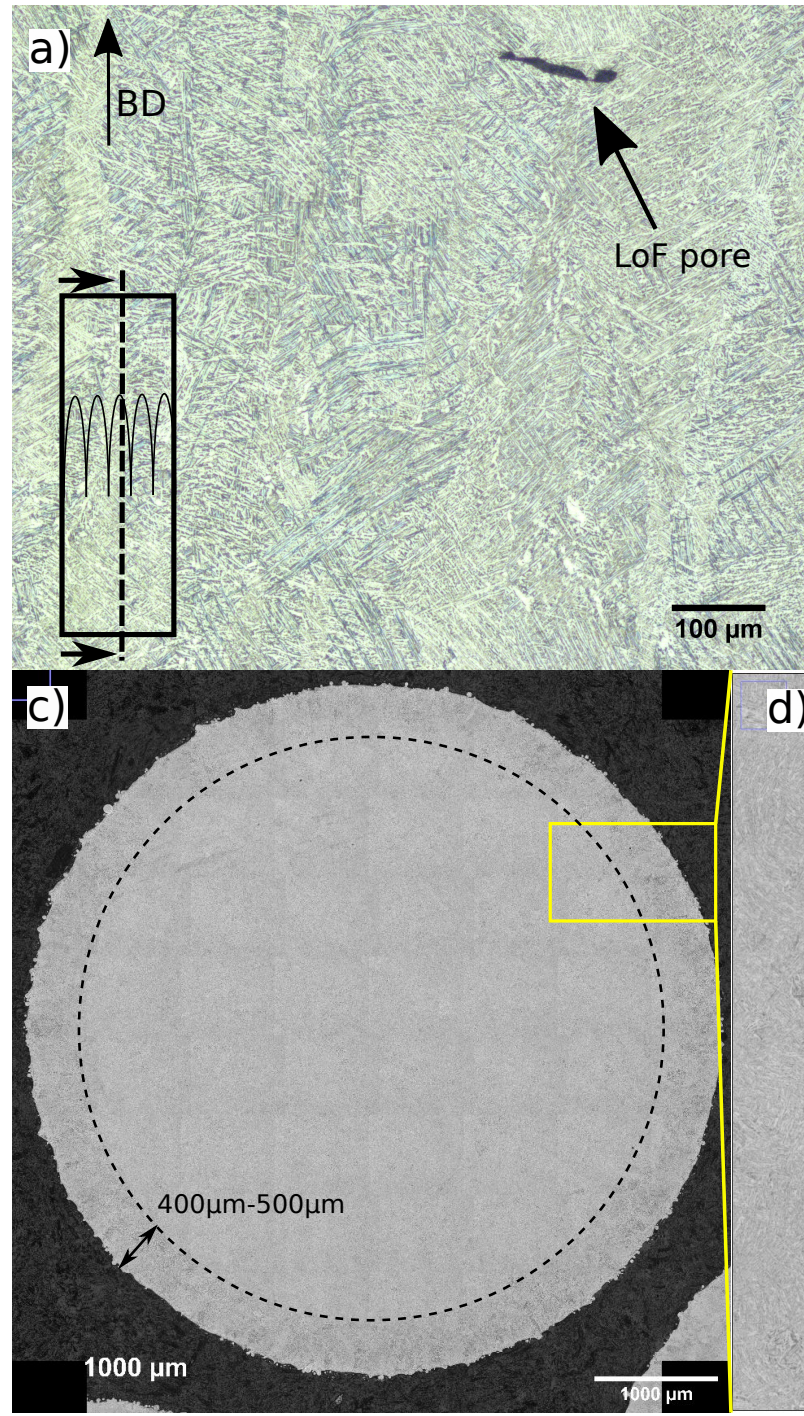

b)

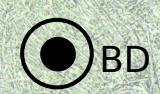

d)

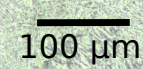

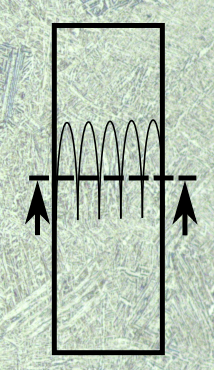

Figure 3: Microstructure of machined specimens (a) in a plane parallel to the build direction and (b) in a plane perpendicular to the building direction; (c) and (d): the microstructure close to the surface of as-built specimens in a perpendicular plane

For the as-built specimens (Figure 3c and Figure 3 d), a sub-surface ring of 400 to $500 \mu \mathrm{m}$ in 
thickness can be seen in which the microstructure is coarser than the microstructure in the bulk. Micro-hardness measurements using a HV0.2kg indenter showed that the average micro-hardness in sub-surface zone is higher than that measured in the bulk (440 HV0.2 versus 370 HV0.2). The higher hardness in the sub-surface layer may be linked to the formation of alpha case phase (i.e. oxygen-enriched surface phase) that occurs when the alloy is exposed to heated air or oxygen. This phase transformation can occur during either the fabrication or the heat treatments. For the machined specimens, the micro-hardness is homogeneous and similar to the micro-hardness measured in the bulk of the as-built specimens.

Characterisation of the porosity was conducted on 3 specimens for each configuration on planes perpendicular to the specimen axis (i.e. perpendicular to the building direction). For each configuration, the number of transverse cut planes analysed is between 10 and 20, which result in a total analysed area of between $340 \mathrm{~mm}^{2}$ and $1100 \mathrm{~mm}^{2}$. The smallest pore that was observed is of approximately $5 \mu \mathrm{m}$ in diameter. In addition to the porosity characterisations on polished samples, X-ray tomography observations have been conducted on a small sample in order to visualise the 3D geometry of pores. The two types of pores that were observed are gas pores and LoF pores. While gas pores are generally spherical, the LoF pores, related mainly to the balling effect [15], have a very spread-out geometry, i.e. a large area but small thickness. The plane on which pores spread out is generally perpendicular to the building direction. Figure 4 shows the geometries of a gas pore and a LoF pore observed by X-ray tomography. These observations are in a good agreement with the literature [18]. The porosity levels measured on polished samples are very low, approximately $0.001 \%$. The pore density, characterised by the number of pores per $\mathrm{mm}^{2}$, is approximately $1.08 \times 10^{-2}$ pores $/ \mathrm{mm}^{2}$ for LoF pores. For gas pore, the density is higher, approximately $3.29 \times 10^{-2}$ pores $/ \mathrm{mm}^{2}$.

Surface roughness characterisations were realised thanks to an optical 3D profilometer on 3 specimens for each configuration. A scan of an as-built surfaces by the profilometer is illustrated in Figure $5 \mathrm{a}$ and the same zone observed using an Scanning Electronic Microscope (SEM) is shown in Figure 5 b.

It can be seen that the as-built surface is principally made up of un-melted particles (in red) and valleys in well-melted zones (in dark blue). These singularities are distributed homogeneously 

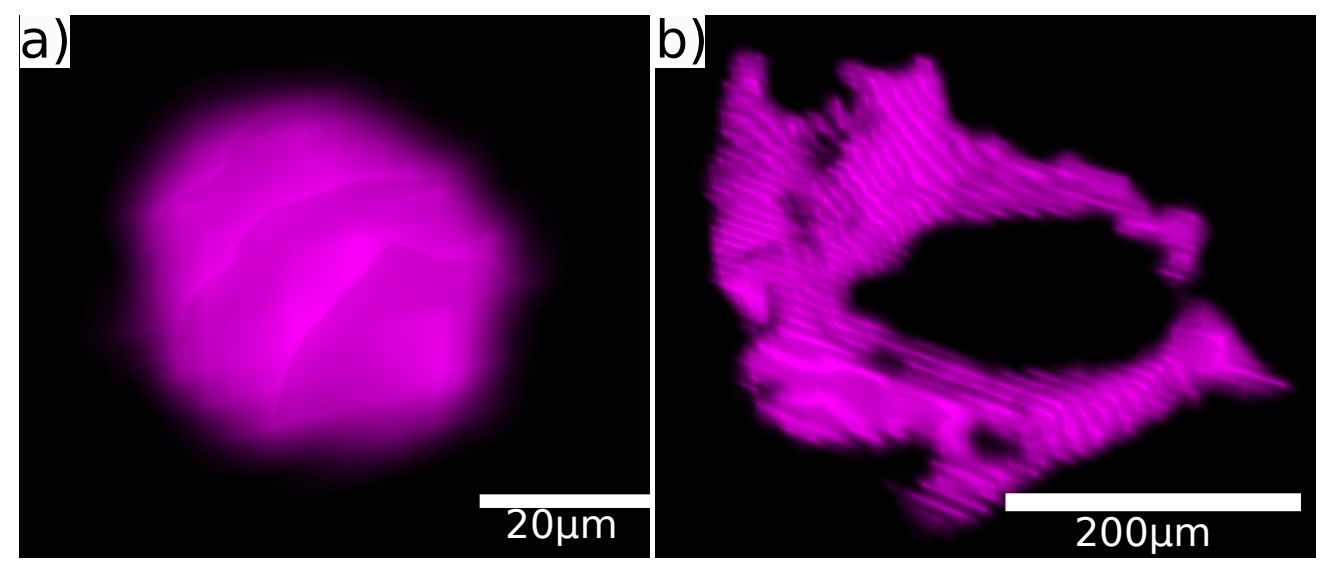

Figure 4: (a) A gas pore and (b) a LoF pore observed by X-ray micro-tomography
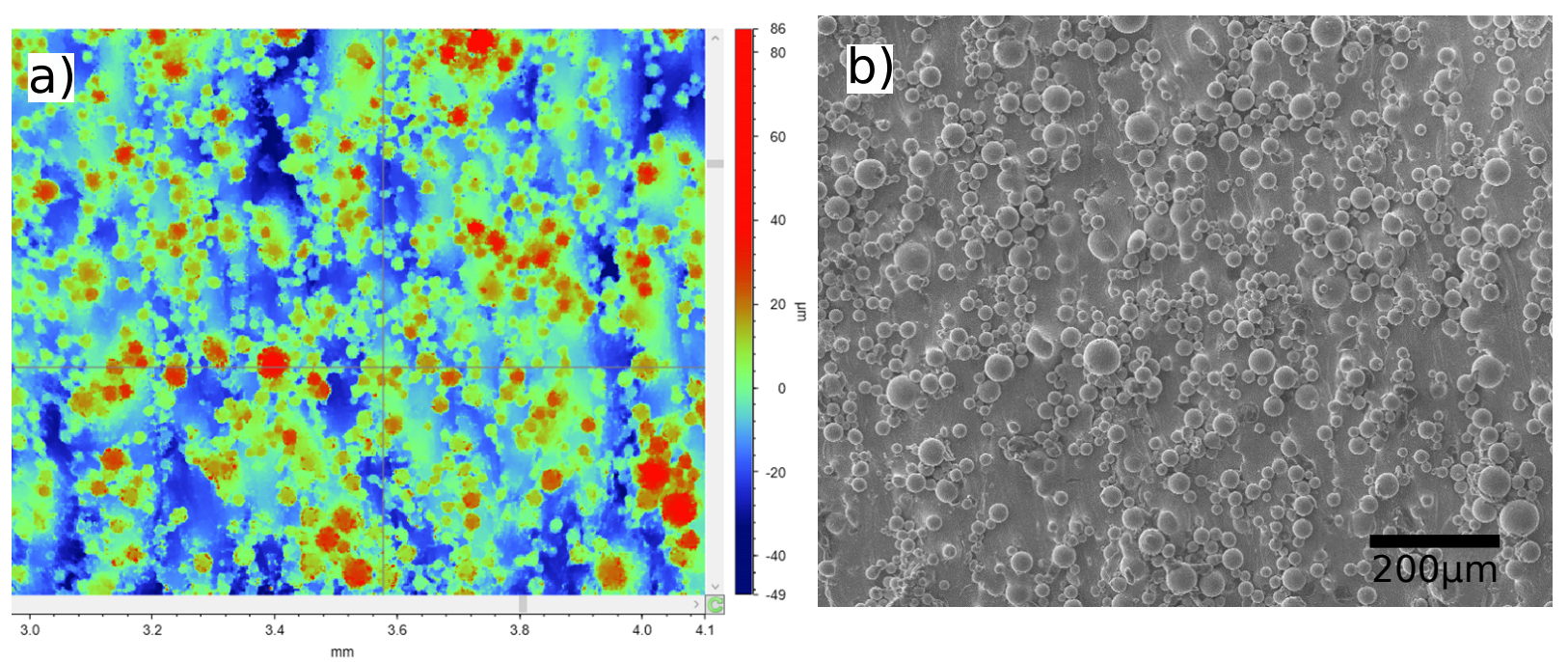

Figure 5: Surface topography of as built specimen (a) Surface scanned by a 3D profilometer; (b)The same surface area observed by a SEM

on the specimen surface and no noticeable effect of the gas flux was observed on the surface. The surface roughness is evaluated in zones with a size of $20 \mathrm{~mm} \times 1 \mathrm{~mm}$ for standard size specimens and $6 \mathrm{~mm} \times 1 \mathrm{~mm}$ for small size specimens. The $2 \mathrm{D}$ surface roughness $S_{a}$, defined as the double integral of the height/depth of peaks are calculated over the evaluation zone after removing the surface wavelength by using a Gaussian filter with the cut-off wavelength $\lambda_{c}$ of $2.5 \mathrm{~mm}$. The resulting measured $S_{a}$ values are given in Table 3. It can be seen that the difference in surface roughness between the standard size specimens and small size specimens is negligible. 
Quasi-static tensile tests were conducted as per the standard ASTM E8/E8M-13 on flat specimens with a rectangular cross-section of $2 \mathrm{~mm} \times 6 \mathrm{~mm}$. The strain was measured using an extensometer with an initial length $L_{0}=25 \mathrm{~mm}$ and a displacement range $\Delta L= \pm 2.5 \mathrm{~mm}$. All tests were conducted with a constant strain rate of $0.005 \mathrm{~min}^{-1}$ at ambient temperature and environment. The tensile properties of the investigated materials are given in Table 3 .

\begin{tabular}{|c|c|c|c|c|c|c|}
\hline Configuration & $\begin{array}{c}\mathrm{E} \\
(\mathrm{GPa})\end{array}$ & $\begin{array}{l}\sigma_{y, 0.2} \\
(\mathrm{MPa})\end{array}$ & $\begin{array}{c}\sigma_{u} \\
(\mathrm{MPa})\end{array}$ & $\begin{array}{c}\mathrm{A} \\
(\%)\end{array}$ & $\begin{array}{c}\mathrm{Sa} \\
(\mu \mathrm{m})\end{array}$ & $\begin{array}{c}\mu \text {-hardness } \\
(\mathrm{Hv} 0.2)\end{array}$ \\
\hline Standard size - Machined & \multirow{2}{*}{112} & \multirow{2}{*}{849} & \multirow{2}{*}{991} & \multirow{2}{*}{8} & $<0.5$ & \multirow{2}{*}{370} \\
\hline Small size - Machined & & & & & $<0.5$ & \\
\hline Standard size - As-built & \multirow{2}{*}{103} & \multirow{2}{*}{839} & \multirow{2}{*}{927} & \multirow{2}{*}{13.8} & $\approx 9.9$ & \multirow{2}{*}{$\begin{array}{c}440 \text { on surface } \\
370 \text { in bulk }\end{array}$} \\
\hline Small size - As-built & & & & & $\approx 10.5$ & \\
\hline
\end{tabular}

Table 3: Tensile properties, surface roughness and micro-hardness of the investigated materials

\section{Fatigue behaviour and damage mechanisms}

All fatigue tests were carried out at ambient temperature and pressure in laboratory air. The fatigue tests were conducted with a constant stress amplitude, a load ratio $\mathrm{R}=0.1$ and a frequency of $20 \mathrm{~Hz}$. A maximum fatigue life of $2 \times 10^{6}$ cycles was used. The reasons for which the fatigue tests were interrupted at $2 \times 10^{6}$ cycles are: (i) the industrial partners of the project are interested in the fatigue behaviour for fatigue lives between $10^{5}$ and $2 \times 10^{6}$ cycles; (ii) due to the requirements of the industrial partners, the testing frequency was limited to $20 \mathrm{~Hz}$; at this frequency, longer fatigue lives were not possible due to time and budgetary limitations; (iii) as widely shown in the literature, even at a fatigue life of $2 \times 10^{6}$ cycles, the presence of defects has a pronounced effect on the fatigue behaviour of additively manufactured metals. The stopping criterion was chosen to be the complete rupture of the specimen. The run-out specimens that survived $2 \times 10^{6}$ cycles were re-tested at a higher load. The principal aims of the re-tests is to gain access to the critical defect for all of the specimens in order to obtain a large enough database with a limited number of specimens. Because only the specimens that survived $2 \times 10^{6}$ cycles were re-tested, the authors 
supposed that the strengthening or the cumulative damage is not significant at such a high number of cycles.

\subsection{Wöhler curves}

The experimental results, in the form of Wöhler curves, are shown in Figure 6 for the machined specimens and in Figure 7 for the as built specimens. The fitting curves corresponding to a probability of failure of $10 \%, 50 \%$ and $90 \%$ were calculated using the Stromeyer equation, defined as follows:

$$
\log _{10} N_{f}=C-m \times \log _{10}\left(S_{\text {max }}-S_{0}\right)
$$

The three parameters in this equation, $C, S_{0}$ and $m$ are fitted using the Maximum Likelihood Estimation (MLE) method. It must be to note that the re-tested points were neglected while the run-out points were taken into account in the fitting algorithm. The detail of the algorithm was shown in the work of Pollak et al. [19]. From the fitting equation, the fatigue limit at $2 \times 10^{6}$ cycles, $S_{D}$, and the associated standard deviation, Std, were calculated.

It can be seen that for the machined specimens (Figure 6a and Figure 6b) the scatter in the fatigue data is relatively high with a covariance, $S t d / S D$, between $12 \%$ and $16 \%$. Furthermore, it seems that the data is grouped into two different populations. This is especially clear for the small size machined specimens. The first population, on the left of the diagram, includes points with $N_{f}$ lower than $10^{5}$ cycles even for low applied stresses. The second population on the right includes specimens which have much higher fatigue strength with $N_{f}$ between $10^{5}$ and $2 \times 10^{6}$ cycles. A comparison with data from the literature [1, 4, 21-23] in Figure 6c shows that the fatigue strength of the investigated material is relatively good. Most of the data points are comparable to the wrought Ti-6Al-4V material. However, the scatter is higher in comparison with the AM data from the literature.

For the as-built specimens (Figure $7 \mathrm{a}$ and Figure $7 \mathrm{~b}$ ), the scatter in the S-N data is much lower, with a covariance between $5.5 \%$ and $8.6 \%$. The comparison with data from the literature [1, 4] in Figure $7 \mathrm{c}$ also shows that the fatigue strength of the material in the present investigation is slightly better. 


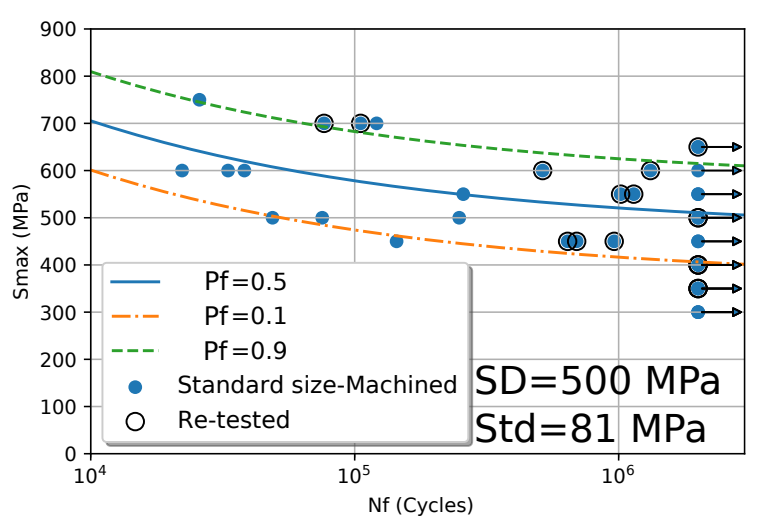

(a) Standard size machined

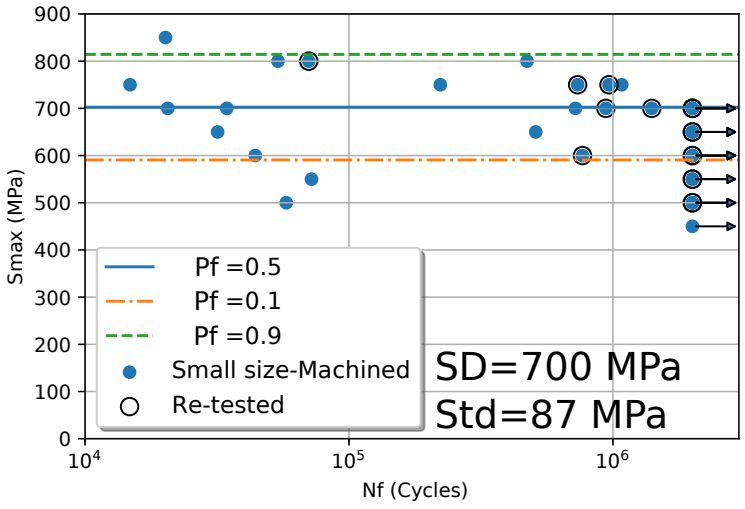

(b) Small size machined

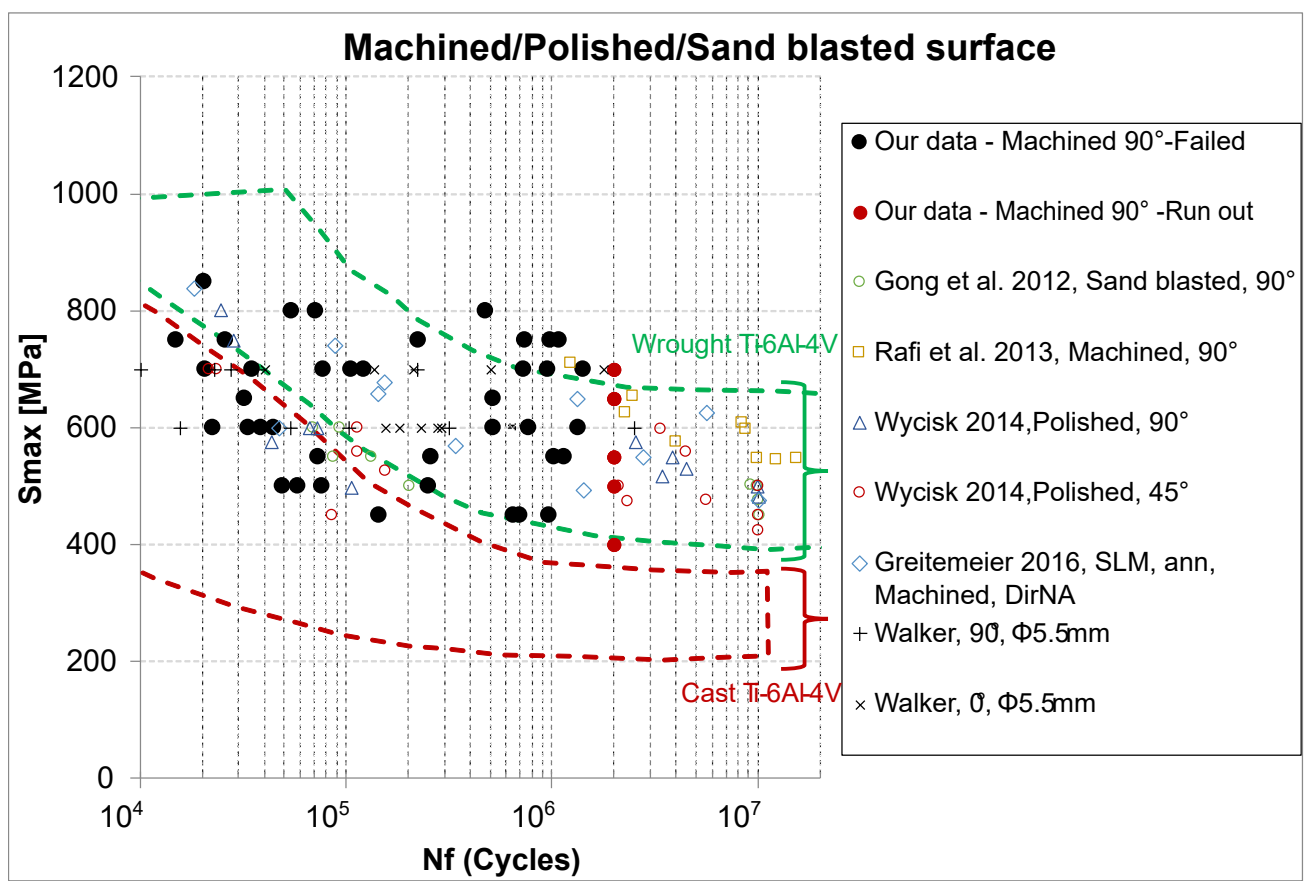

(c) Comparison with the literature

Figure 6: Wöhler curves for (a) standard size machined specimens, (b) small size machined specimens and (c) comparison with data from the literature. The bands for wrought and cast Ti-6Al-4V are from [20] "Titanium: a technical guide"

In order to estimate the effect of the as-built surface, a comparison between the as-built and machined specimens is given in Figure 8. It can be stated that the as-built surface drastically reduces the fatigue strength of the material: the fatigue strength at $2 \times 10^{6}$ cycles for the as- 


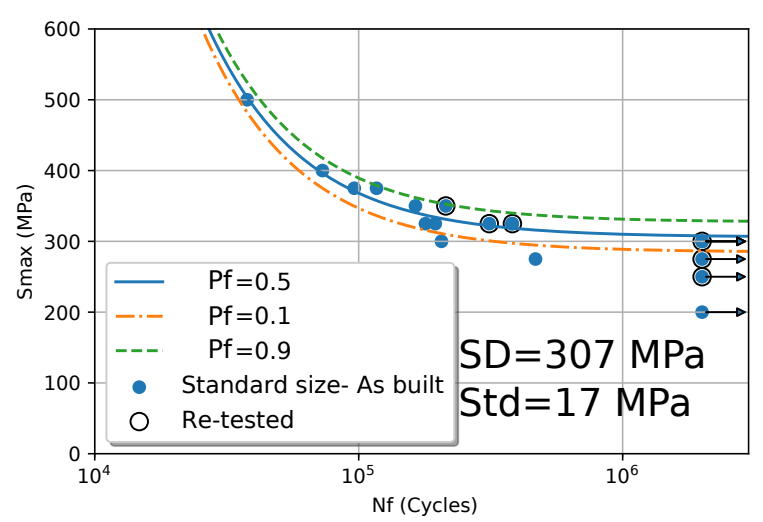

(a) Standard size as-built

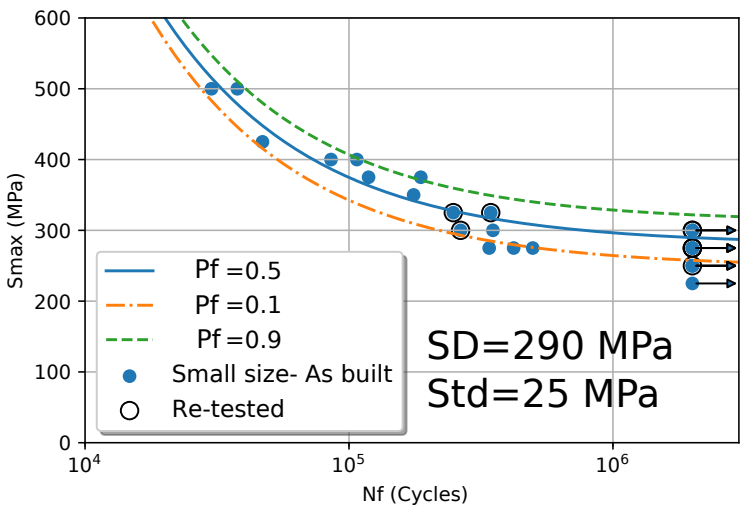

(b) Small size as-built

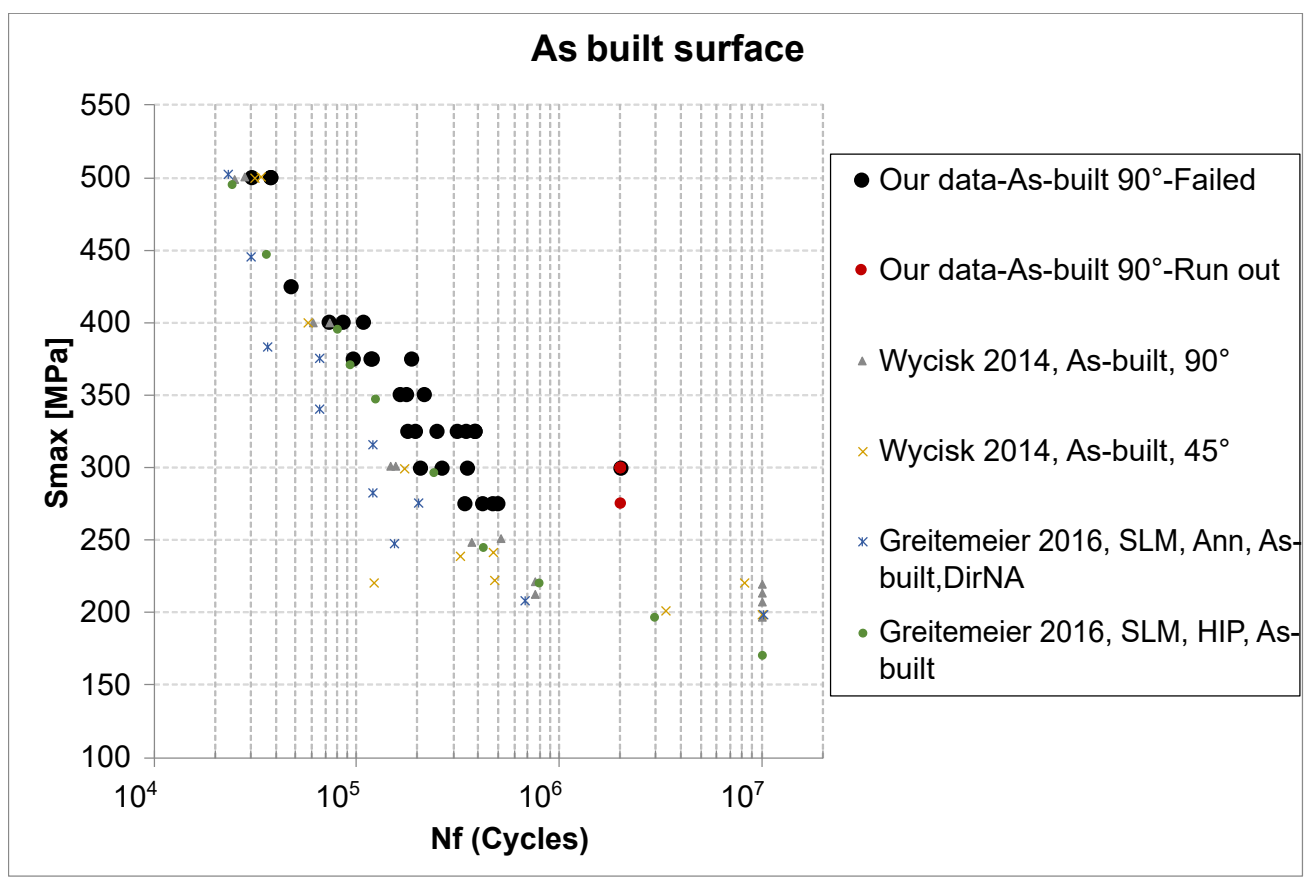

(c) Comparison with the literature

Figure 7: Wöhler curves for (a) as-built standard size specimens, (b) as-built small size specimens and (c) comparison with data from the literature

built specimens is approximately $40 \%$ to $60 \%$ lower than the machined specimens. However, this comparison shows only a macroscopic view of the effect of the as-built surface while the fatigue damage mechanisms have not been taken into account. Later in the paper, a detailed comparison between the machined and as-built specimens for a same crack initiation mechanism 
will be presented.

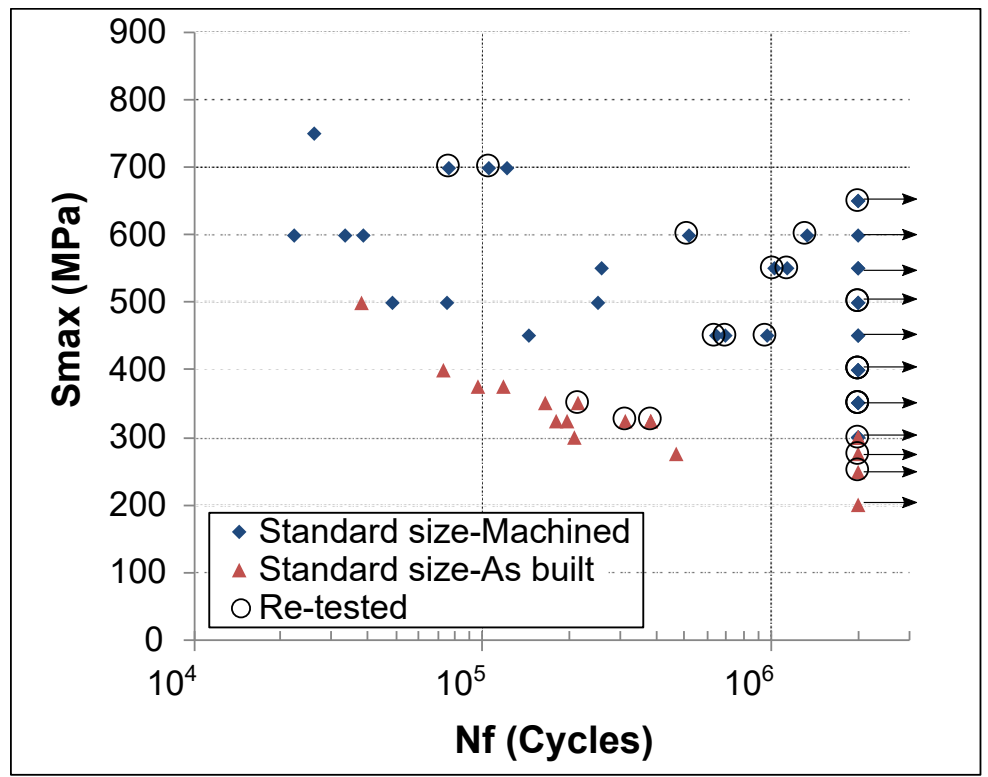

(a) Standard size specimens

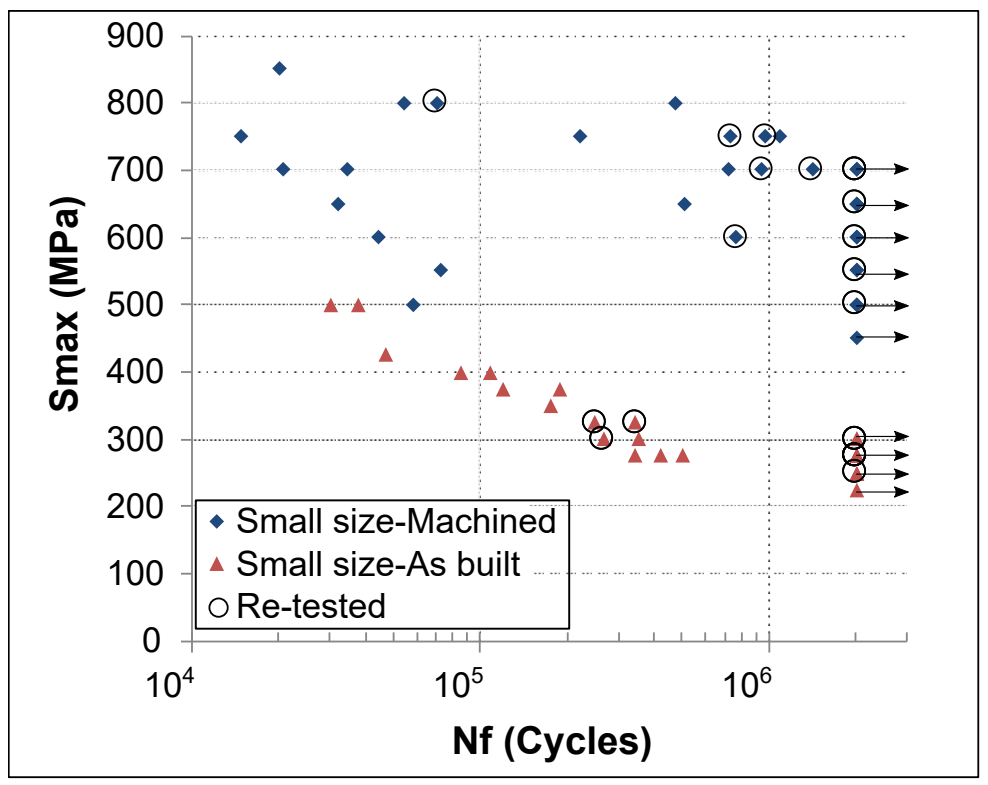

(b) Small size specimens

Figure 8: Comparison between the Wöhler curves for the machined specimens and the As-built specimens for (a) standard size specimens and (b) small size specimens 


\subsection{Fatigue crack initiation mechanisms}

All of the fatigue failure surfaces were analysed using a scanning electronic microscope in order to identify the origin of crack initiation and to measure the defect size. For the machined specimens, four crack initiation mechanisms were identified:

- LoF pores at the free surface (Figure 9a)

- LoF pores in the bulk (Figure 9b)

- Gas pores at the free surface (Figure 9r)

- Gas pores in the bulk (Figure $9 \mathrm{~d}$ )

For the as-built specimens, only the following two crack initiation mechanisms were observed:

- LoF pores at the free surface (Figure 10 a)

- Surface roughness (Figure 10b), multi-site crack initiation often observed

A summary of the crack initiation mechanisms observed in all of the batches is given in Table 4. It can be seen that crack initiation from LoF pores at surface is the most likely to occur. The

\begin{tabular}{|c|c|c|c|c|c|}
\hline Geometry & $\begin{array}{c}\text { LoF pore } \\
\text { on surface }\end{array}$ & $\begin{array}{c}\text { LoF pore } \\
\text { in bulk }\end{array}$ & $\begin{array}{c}\text { Gas pore } \\
\text { on surface }\end{array}$ & $\begin{array}{c}\text { Gas pore } \\
\text { in bulk }\end{array}$ & Roughness \\
\hline Standard size machined & 10 & 8 & 2 & 0 & 0 \\
\hline Small size machined & 7 & 5 & 4 & 3 & 0 \\
\hline Standard size As-built & 12 & 0 & 0 & 0 & 2 \\
\hline Small size As-built & 7 & 0 & 0 & 0 & 8 \\
\hline
\end{tabular}

Table 4: A summary of the number of specimens in which the different crack initiation mechanisms were observed for the different specimen types and sizes

probability of occurrence of surface LoF pores is between $37 \%$ and $85 \%$. For the as-built specimens, neither gas pores nor internal LoF pores were observed at the crack initiation sites. Another interesting observation that can be made is that the probability of occurrence of LoF pores at the 


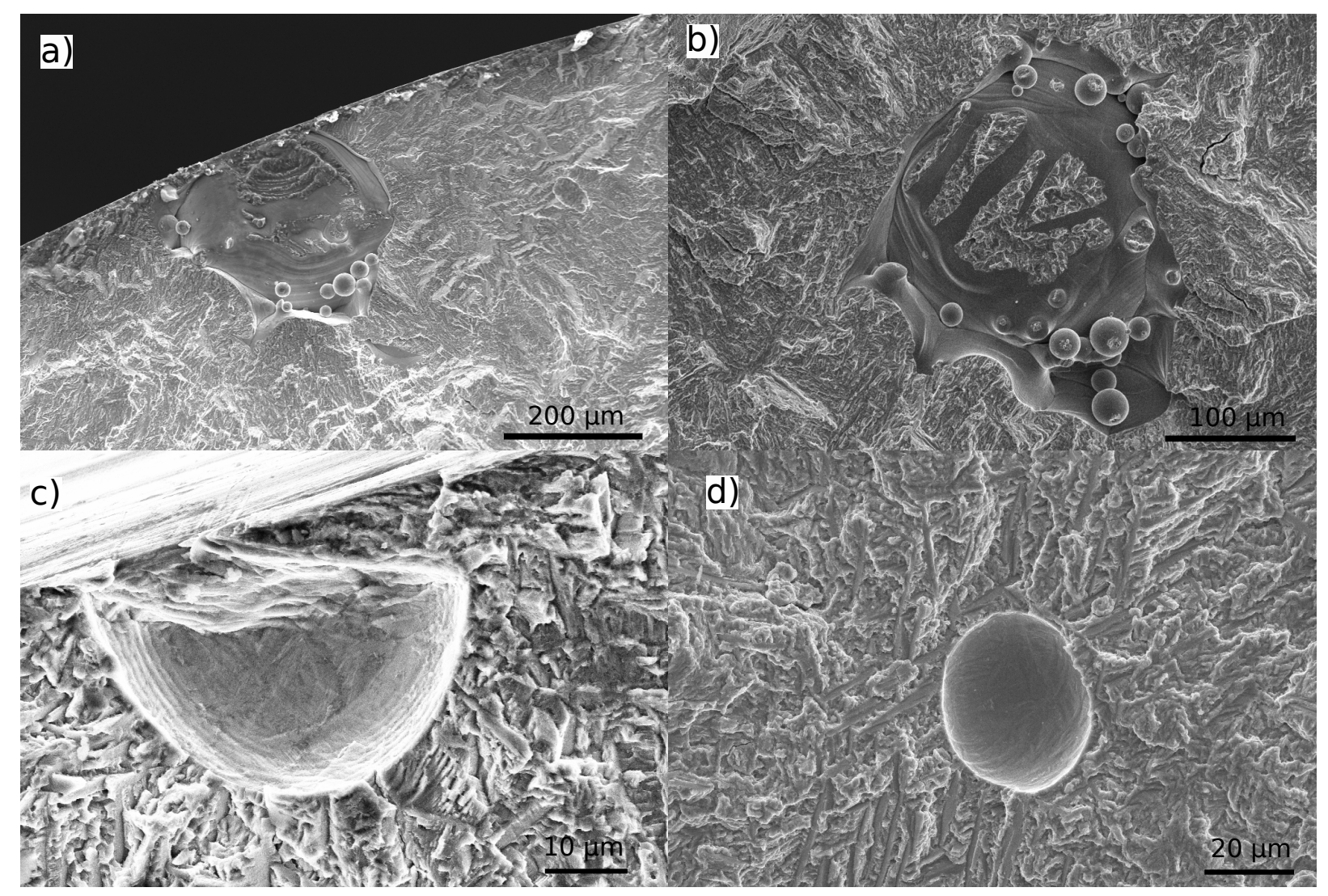

Figure 9: The four defect types observed in the machined specimens at the crack initiation sites: (a) LoF pore at the surface, (b) LoF pore in the bulk, (c) Gas pore at the surface, (d) Gas pore in the bulk

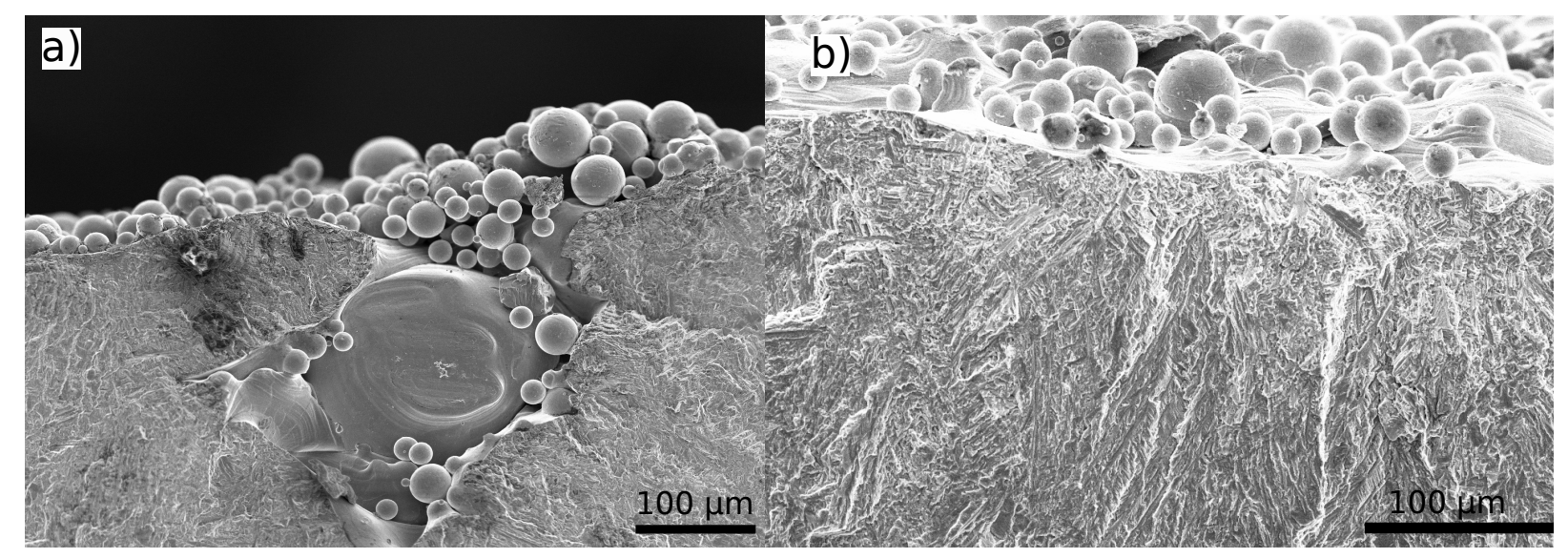

Figure 10: The two crack initiation mechanisms observed at the crack initiation sites: (a) One site crack initiation from a LoF pore at the surface; (b) Multi-site crack initiation from the surface roughness 
surface for the standard size specimens is higher than for the small size specimens. This is true for both machined and as-built surfaces. This observation will be analysed more closely in Section 4 with respect to the statistical size effect.

The size of all of the critical pores at the crack initiation sites was measured and is expressed using the square root of the area parameter, $\sqrt{\text { area }}$. Regarding the crack initiation mechanism related to the surface roughness, in this work no relevant size parameter was found that could be compared to the $\sqrt{\text { area }}$ parameter used for pores. In fact, the surface roughness defects are generally narrow (with a depth smaller than $50 \mu \mathrm{m}$ ) but very long. For this reason, the area measure on the failure surface does not seem relevant. Other parameters such as the depth and the bottom curvature of the local surface valleys might be more significant [24, 25].

The pore size distributions are shown in Figure 11 in terms of the reduced variable, $Y_{j}$, associated with the Gumbel distribution. The reduced variable is calculated from the empirical cumulative density function, $F_{j}$, as follows:

$$
Y_{j}=-\operatorname{Ln}\left(-\operatorname{Ln}\left(F_{j}\right)\right)
$$

The mean value and the standard deviation of the pore size are given in Table 5 .

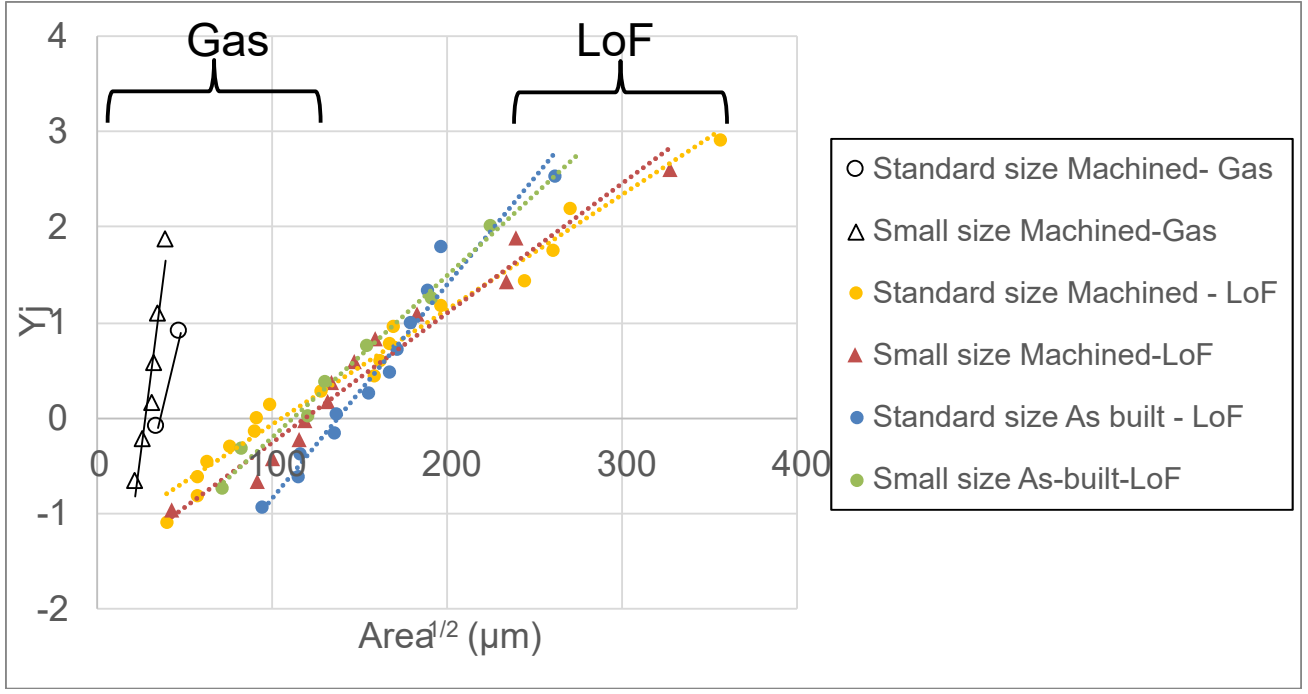

Figure 11: Distributions of the critical pore size measured at the crack initiation sites in a linearized Gumbel space

It can be seen that the size of the critical gas pores is generally lower than $50 \mu \mathrm{m}$ while the critical LoF pores have a size between $50 \mu \mathrm{m}$ and $350 \mu \mathrm{m}$, with an average value of approximately 


\begin{tabular}{|c|c|c|}
\hline Configuration & $\begin{array}{c}\text { LoF Pore size } \\
\text { Mean }(\mathrm{Std})[\mu \mathrm{m}]\end{array}$ & $\begin{array}{c}\text { Gas Pore size } \\
\text { Mean }(\mathrm{Std})[\mu \mathrm{m}]\end{array}$ \\
\hline Standard size-Machined & $149(89)$ & $41(9)$ \\
\hline Small size-Machined & $156(75)$ & $31(6)$ \\
\hline Standard size- As-built & $160(45)$ & - \\
\hline Small size- As-built & $140(55)$ & - \\
\hline
\end{tabular}

Table 5: The mean value and standard deviation of the size of the critical pores observed at the crack initiation sites expressed in terms of their $\sqrt{\text { area }}$

$150 \mu \mathrm{m}$. For the LoF pores, the average pore size is similar in all of the specimen configurations. It means that there is no difference of the LoF pore size between the machined and as-built specimens. Also, there is no difference between the standard size specimens and small size specimens. This observation is surprising at first glance because as per the theory of extreme values [26, 27], the maximum pore size in a volume should increase with increasing volume. However, it was shown in the work of El Khoukhi et al. [28] that there is a threshold in terms of loaded volume, beyond which the critical pore size does not change with increasing volume. The authors showed that the value of this threshold depends on different factors such as the pore size distribution and the inter-pores distance. Thanks to this result, it can be assumed that the "threshold" volume related to LoF pore distribution has already been reached even with the small size specimens.

\section{Links between the fatigue strength and crack initiation mechanisms}

In this section, the relationship between the crack initiation mechanisms and the fatigue behaviour will be quantitatively characterised. More precisely, the S-N curves will be analysed separately for each crack initiation mechanism. The pore size is also taken into account by using a "corrected stress" parameter. Thanks to these analyses, two important questions will be answered:

- What is the effect of the size and the spatial position of the pores?

- What is the effect of the as-built surface? For the same crack initiation mechanism from pores, is there a difference between the machined and the as-built specimens. 


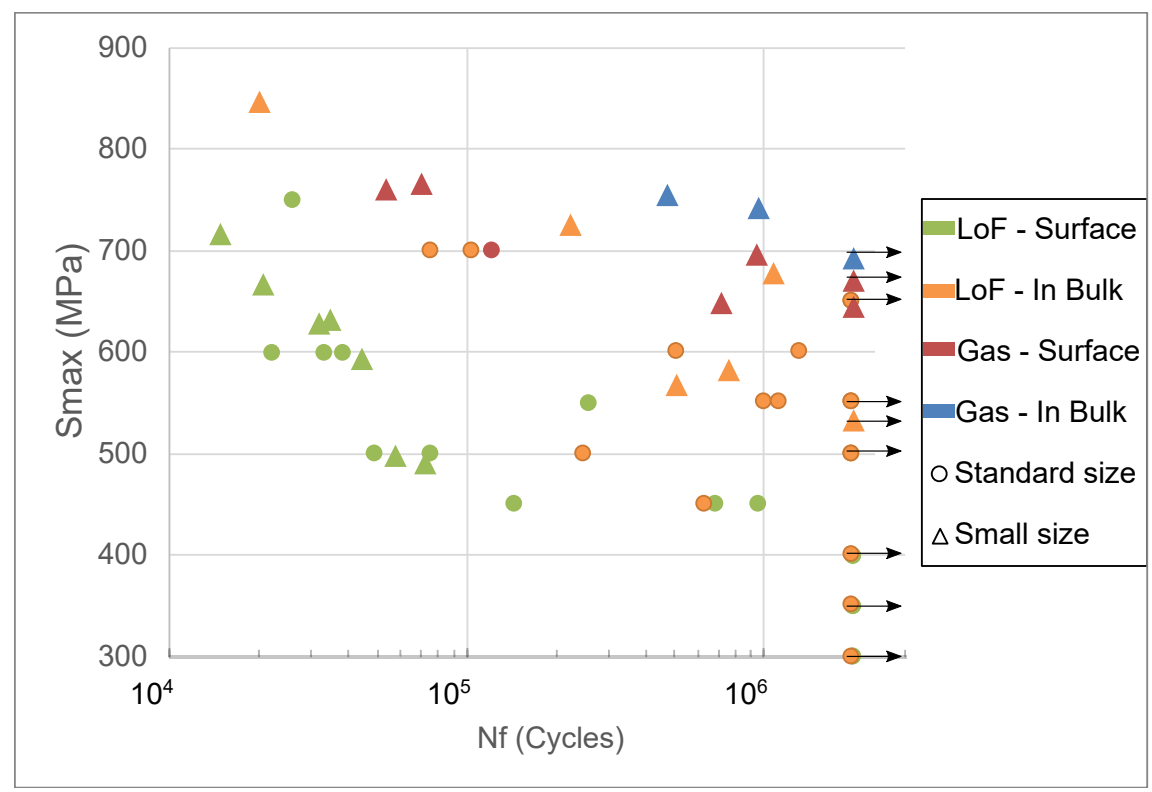

Figure 12: Correlation between the fatigue strength and the fatigue damage mechanisms for the Machined specimens. Note that the small size specimens do not have a constant gauge section. For these specimens the applied stress is calculated at the crack position which does not necessarily correspond to the smallest diameter.

\subsection{Machined specimens}

Figure 12 shows the $\mathrm{S}-\mathrm{N}$ data for the machined specimens, in which the different crack initiation mechanisms are highlighted. The different initiation mechanisms can be ranked qualitatively

in terms of which mechanism is the most detrimental or harmful:

1- LoF pores at the surface (the most detrimental)

2- LoF pores in the bulk

3- Gas pores at the surface

4- Gas pores in the bulk (the least detrimental)

It is interesting to note that, for the investigated material, a large internal LoF pore (with an average size of $150 \mu \mathrm{m}$ - Table 5) can be more detrimental than a small surface gas pore (with an average size of $30 \mu \mathrm{m})$. Regarding the two populations of the fatigue strength mentioned earlier in Section 2.1, the population with low fatigue strength is related to the presence of a critical LoF pore at the surface while the second population with higher fatigue strength but greater more scatter, is related to the three other damage mechanisms: LoF pores in bulk, Gas pores on surface and Gas 

mechanisms are highlighted. It can be seen that there are no significant difference in terms of

pores in bulk.

\subsection{As-built specimens}

For the as-built specimens, Figure 13 shows the $\mathrm{S}-\mathrm{N}$ diagram in which the two crack initiation

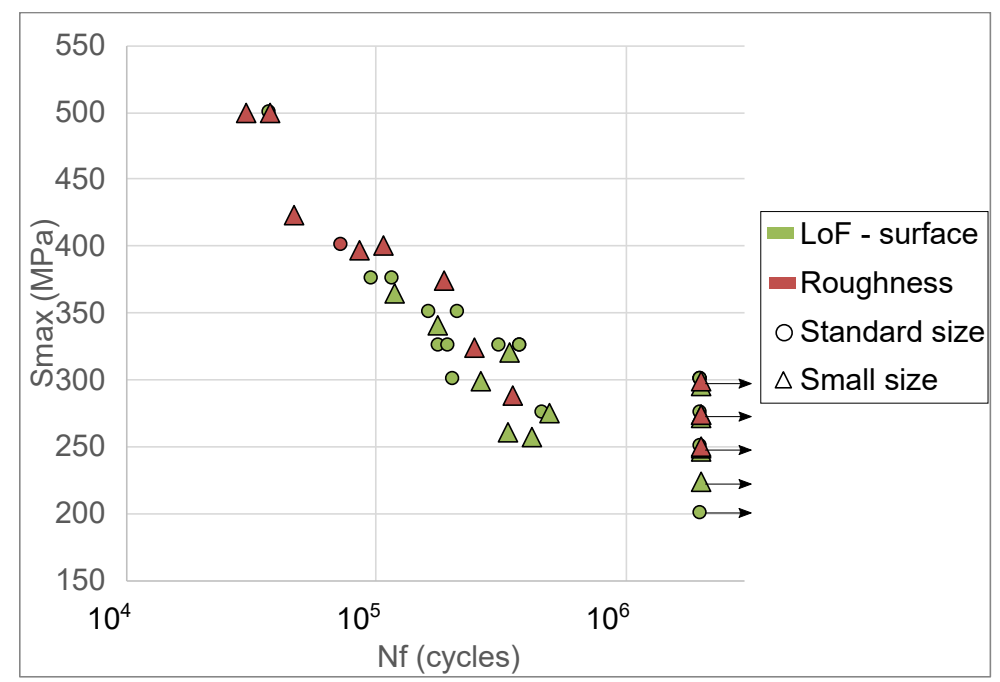

Figure 13: Correlation between the fatigue strength and the fatigue damage mechanisms of the As-built specimens. Note that for the small size specimens the applied stress is calculated using the diameter at the crack position and not the diameter at the smallest section.

the fatigue strength between crack initiation from LoF pores at the surface and crack initiation from surface roughness. This observation is quite surprising because when linked to the defect size as illustrated in Figure 10, the impact of a LoF pore with a depth of approximately $400 \mu \mathrm{m}$ (Figure 10a) is equivalent to a surface roughness defect with a depth of $20 \mu \mathrm{m}$ (Figure 10p). One possible explanation is that the defect aspect ratio, i.e. the ratio between the depth and the length on the surface, is much lower for roughness defects than for LoF pores. According to Molaei et al. [29], the aspect ratio greatly influences the fatigue strength and hence the defect depth alone or the defect area alone are not adequate to fully characterise the effect of the roughness defects. Another factor may also affect the fatigue strength of as built specimens is the sub-surface layer with a more brittle microstructure, as discussed in Section 1.2. The effect of defect size may be less pronounced than for the machined specimens. This hypothesis will be discussed again in the 
comparison of the effect of the LoF pores between the machined surface and as-built surface in the next section.

\subsection{Analysis of $S-N$ data taking into account the crack initiation mechanism and the critical pore} size

In this section, the S-N data will be analysed separately for each crack initiation mechanism. The pore size will also be taken into account in this analysis by using the approach developed in the previous work [15]. This approach, inspired by the work of Caton et al. [30], introduce a "Corrected stress Smax" in which the critical pore size is taken into account, as given in Equation (3). More details related to this approach can be found in previous work published by the authors [15].

$$
\text { Corrected Smax }=S_{\text {max }}\left(\frac{\sqrt{\text { area }}}{\operatorname{average}\left(\sqrt{\text { area }}_{i}\right)}\right)^{s^{\prime}}
$$

The two parameters used in this formula, average $\left({\sqrt{\text { area }_{i}}}\right)$ and $s^{\prime}$, are determined as follows:

- Average $\left(\sqrt{\text { area }}_{i}\right)$ : the average pore size for each defect category. For LoF pores, the mean pore size is $150 \mu \mathrm{m}$. For gas pores, the mean pore size is $30 \mu \mathrm{m}$. The main reason for using the mean pore size is to make it possible to compare the corrected data with the uncorrected S-N curves.

- $s^{\prime}$ : a non-linear weight factor related to the pore size. Higher values of s' result in a more pronounced effect of the porosity. In this work, the parameter $s^{\prime}$ is identified by using the MLE method in which the Stromeyer equation was used to fit the S-N data.

$$
\log _{10} N=C-m \times \log _{10}\left(\text { Corrected } S_{\text {max }}-S_{0}\right)
$$

In short, the four parameters of the model optimised by the MLE method are $s^{\prime}, C, m$ and $S_{0}$, compared to the 3 parameters when using the classical Stromeyer equation as in Section 2.1 .

Figure 14 and Figure 15 show the corrected S-N diagram in comparison with the uncorrected S-N diagram for the machined and the as-built specimens. The identified parameters are given in Table 6. It should be noted that for the mechanism related to gas pore in the bulk for the machined specimens, the MLE estimation was not possible due to the limited number of data. 
Only the fatigue strength was estimated in order to compare with the other mechanisms. For better understanding the comparability between the corrected and uncorrected S-N diagrams, it should be noted that for a pore size equal to the average pore size (as a reminder $150 \mu \mathrm{m}$ for LoF pores and $30 \mu \mathrm{m}$ for LoF pores), the fitting curves presented in the corrected stress diagrams are unchanged when presented in the uncorrected stress diagrams. Similarly, the estimated fatigue strengths in terms of corrected stress shown in Table 6 are unchanged when calculated for uncorrected stress with a pore size equal to the average pore size.

By using the corrected stress that takes into account the pore size, it can be seen that the scatter of the S-N can be reduced, especially for machined specimens. In comparison with the raw S-N curves without regarding neither crack initiation mechanism nor critical defect size (Figure 6), the covariance $\mathrm{Std} / \mathrm{Sd}$ of all of the corrected Smax-Nf are lower than $10 \%$, compared with a covariance up to $16 \%$ for raw Smax-Nf curves.

For machined specimens, it can be seen in Figure $14 \mathrm{a}$ that no significant statistical size effect is observed when the surface LoF pores govern the fatigue crack initiation. In fact, the fatigue strength is similar between the standard size and the small size specimens. However, for LoF pores in the bulk (Figure 14b), a slight effect can be seen. For mechanisms related to gas pores (Figure 14c, Figure 14d), no clear difference can be observed between the standard and small specimens. This observation can be explained by the similar pore size distributions between the standard and small specimens as shown in Figure 11. From this analysis, it can be concluded that the size effect observed for the machined specimens (Figure 6) cannot be clearly explained by analysing the critical pore size. A more detailed discussion is proposed in Section 4

Thanks to the estimated fatigue strength at $2 \times 10^{6}$ cycles, the Kitagawa-Tagahashi diagram for average defect sizes and mean fatigue strength can be drawn as shown in Figure 16 . The horizontal fatigue limit at $2 \times 10^{6}$ cycles is estimated to be $700 \mathrm{MPa}$ from the literature [4, 31, 32] for the AM Ti-6Al-4V alloy with a Hot Isostatic Pressing (HIP) treatment. For the LEFM prediction, a value of the stress intensity factor threshold $\Delta K_{t h}=3.9 \mathrm{MPa} \sqrt{m}$ is used. This value is found in the work of Leuders et al. [33] and corresponds to the SLM Ti-6Al-4V alloy fabricated in the $90^{\circ}$ building direction and a post HIP treatment. The Kitagawa-Takahashi diagram shows that, for the machined specimens, the difference between surface LoF Pores and internal LoF pores is 
LoF pores on surface
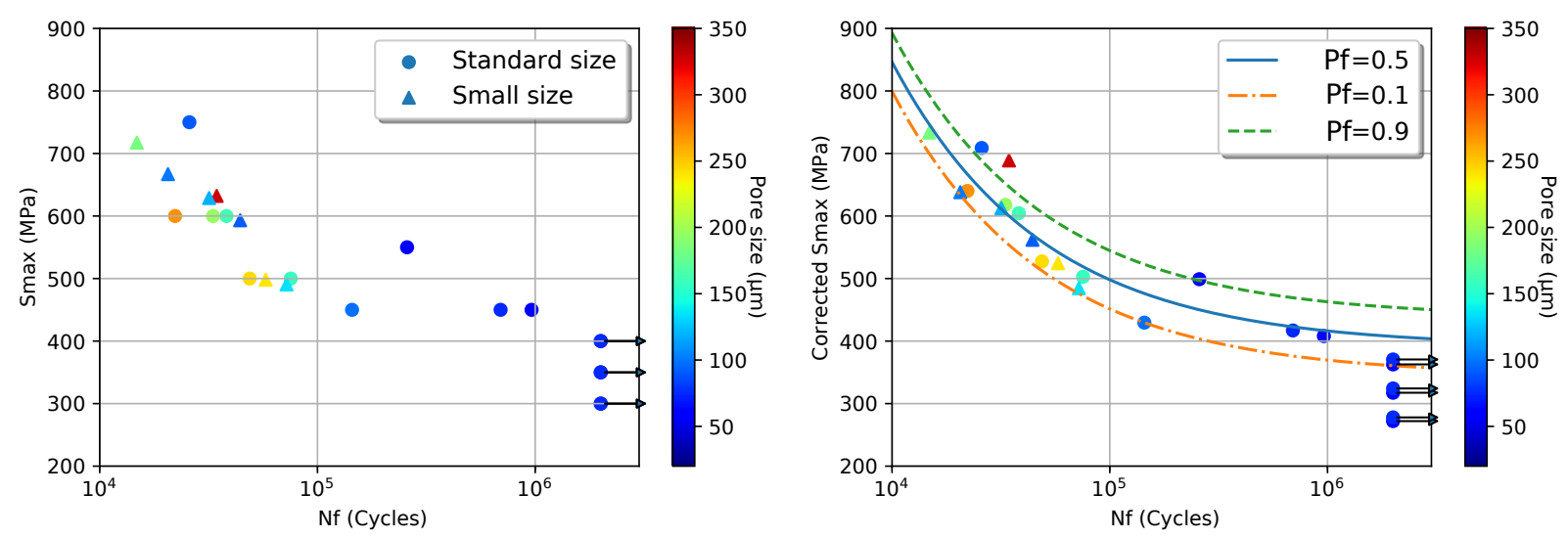

(a) LoF pores on surface-Corrected Smax $=\operatorname{Smax} \times(\sqrt{\text { area }} / 150)^{0.11}$

LoF pores in bulk
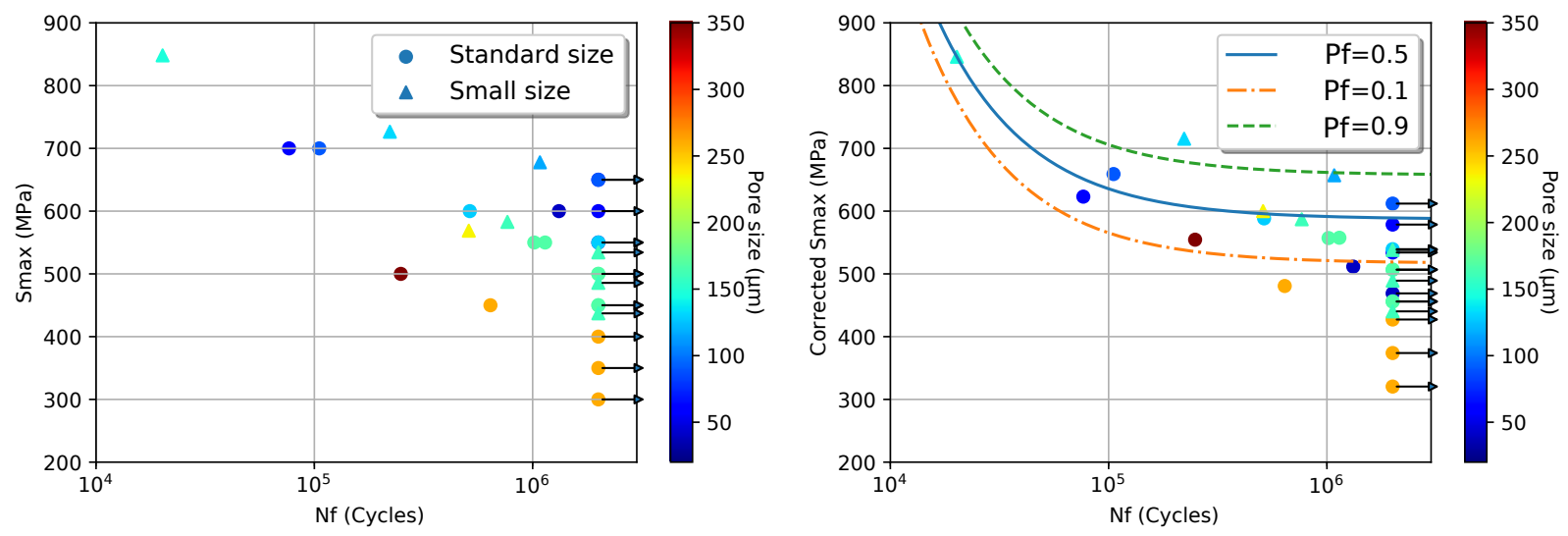

(b) LoF pores in bulk-Corrected Smax $=\operatorname{Smax} \times(\sqrt{\text { area }} / 150)^{0.12}$

Figure 14: Uncorrected and Corrected S-N curves of machined specimens for the crack initiation mechanism related to: (a) LoF pores on surface; (b) LoF pores in bulk

notable: the fatigue strength associated with internal LoF pores is approximately $44 \%$ higher than for surface LoF pores. In terms of fatigue life, it can be seen in Figure $14 \mathrm{a}$ and Figure $14 \mathrm{~b}$ that, at a corrected stress of $600 \mathrm{MPa}$, the fatigue life corresponding to internal LoF pores is approximately 10 times greater than surface LoF pores. The classical Murakami approach [34] which makes a distinction between surface and internal defects is not good enough to accurately predict this difference. In fact, by using a geometry factor of 1.43 for surface defects and 1.56 for internal 
Gas pores on surface
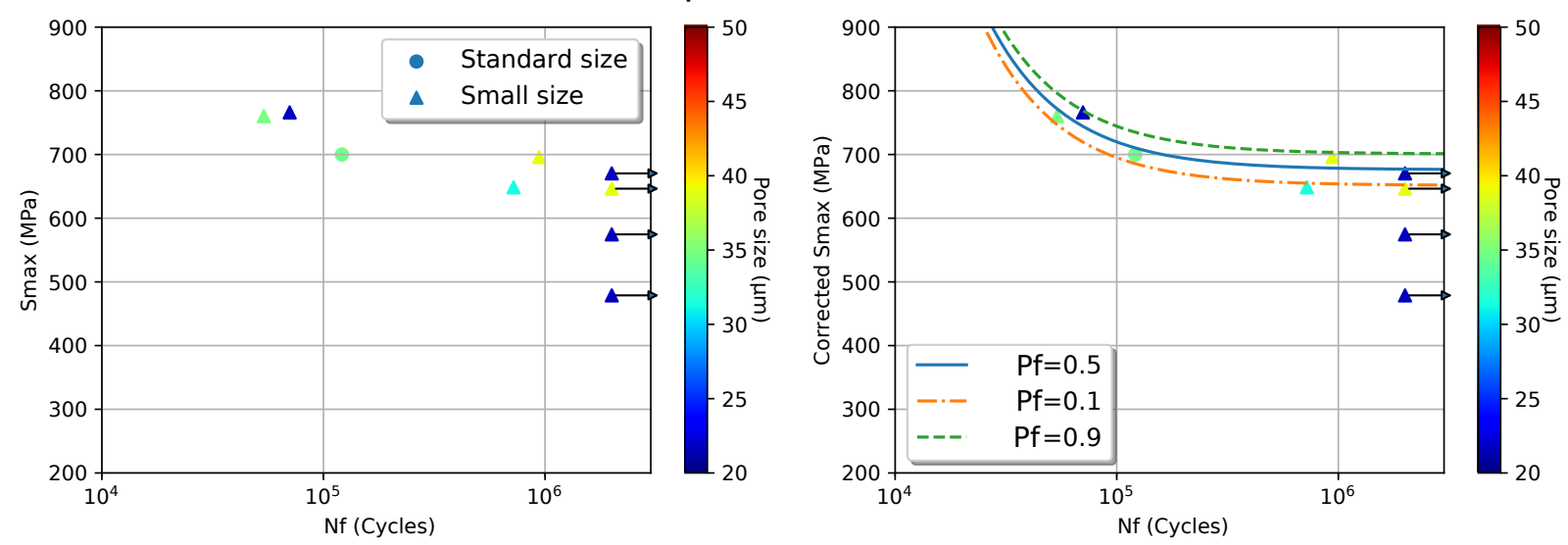

(c) Gas pores at the surface-Corrected Smax $=S \max \times(\sqrt{\text { area }} / 30)^{0}=S \max$

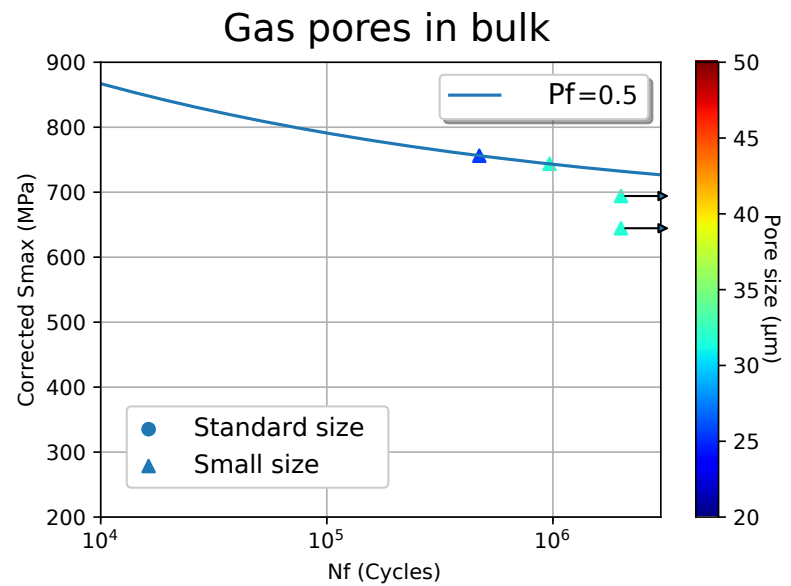

(d) Gas pores in the bulk-Corrected Smax $=\operatorname{Smax} \times$ $(\sqrt{\text { area }} / 30)^{0}=\operatorname{Smax}$

Figure 14: (Continued) Uncorrected and Corrected S-N curves of machined specimens for the crack initiation mechanism related to: (c) Gas pores on surface; (d) Gas pores in bulk

defects, the Murakami approach predicts a factor of 1.1 between the fatigue limits of internal and surface defects while in the present work, a factor of 1.44 is observed. This result is in good agreement with the work of Andreau et al. [35] which showed, for a SLM 316L alloy having a polished contour, that internal defects must have a size of 4 to 10 times greater than surface defects to become critical in fatigue. A lower crack growth rate from internal defects compared to surface defects, as shown in the work of Junet el al. [36] for Ti-6Al-4V alloy or in the work of Serrano- 
LoF pores on surface - As built
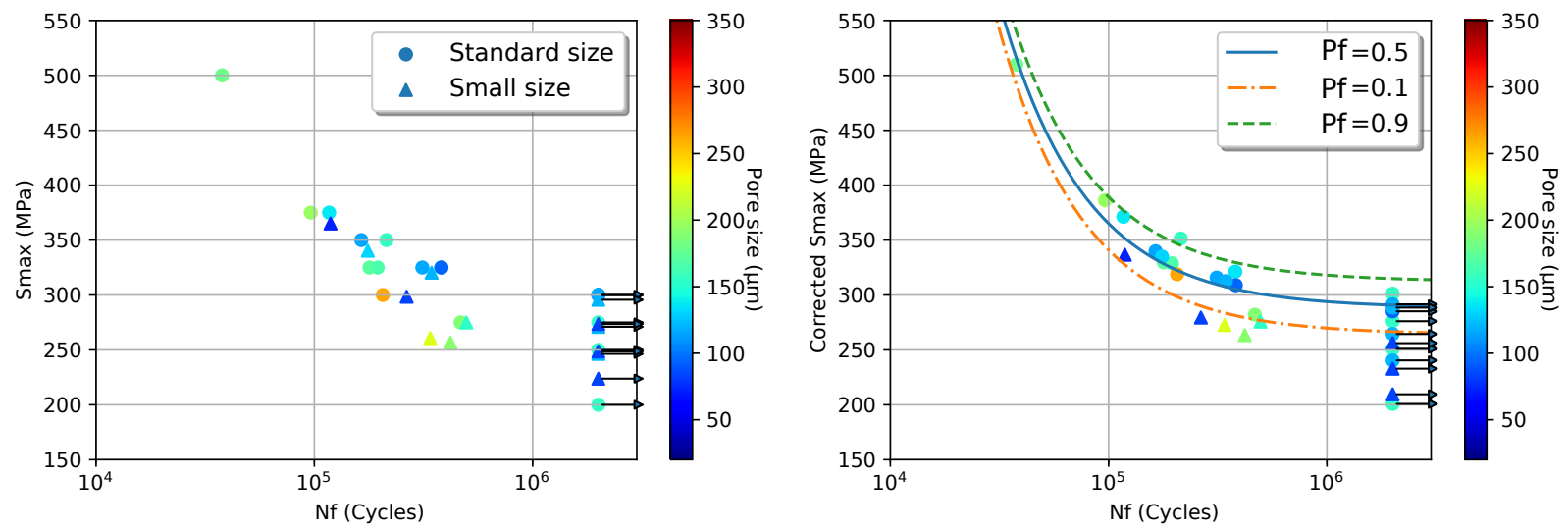

(a) LoF pores on surface-Corrected Smax $=\operatorname{Smax} \times(\sqrt{\text { area }} / 150)^{0.11}$

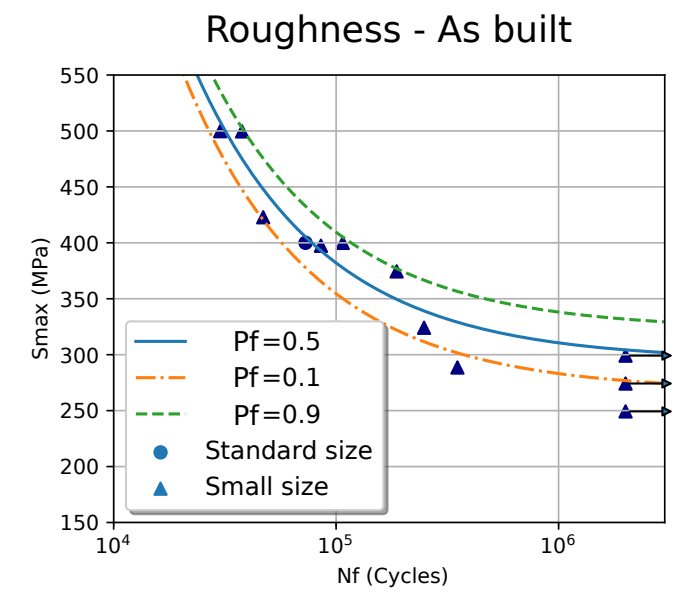

(b) Rougness

Figure 15: (a) Uncorrected and Corrected S-N curves of as-built specimens for the crack initiation mechanism related to LoF pores on surface; (b) Uncorrected S-N curves of as-built specimens for the crack initiation related to surface roughness

Munoz et al. [37] for a cast aluminium alloy, also contributes to a higher fatigue strength for the internal LoF pore related mechanism. It can also be stated that the classical LEFM approach with a value of $\Delta K_{t h}=3.9 \mathrm{MPa} \sqrt{m}$ under-estimates the fatigue strength related to the surface LoF pores mechanism for machined specimens. For as built specimens, the prediction seems better. However, it must be kept in mind that the effect of several factors such as the interaction with the surface roughness or the effect of the sub-surface layer is not fully understood. 


\begin{tabular}{|c|c|c|c|c|c|c|}
\hline Mechanism & $\begin{array}{c}\text { Corrected Smax } \\
\text { formula }\end{array}$ & $\mathrm{m}$ & $\mathrm{C}$ & $S_{0}$ & \multicolumn{2}{|c|}{$\begin{array}{r}\text { Fatigue strength (corrected Smax) } \\
\text { at } 2 \times 10^{6} \text { cycles }\end{array}$} \\
\hline Machined - LoF on surface & $S_{\max } \times\left(\frac{\sqrt{\text { area }}}{150}\right)^{0.11}$ & -1.6 & 8.2 & 391 & 407 & 36 \\
\hline Machined - LoF in bulk & $S_{\max } \times\left(\frac{\sqrt{\text { area }}}{150}\right)^{0.12}$ & -0.95 & 6.6 & 587 & 589 & 55 \\
\hline Machined - Gas on surface & $S_{\max } \times\left(\frac{\sqrt{\text { area }}}{30}\right)^{0}$ & -0.79 & 6.3 & 676 & 677 & 19 \\
\hline Machined - Gas in bulk & $S_{\max } \times\left(\frac{\sqrt{\text { area }}}{30}\right)^{0}$ & N/A & N/A & N/A & $732 *$ & N/A \\
\hline As-built - LoF on surface & $S_{\text {max }} \times\left(\frac{\sqrt{\text { area }}}{150}\right)^{0.11}$ & -0.9 & 6.7 & 288 & 290 & 18.8 \\
\hline As-built - Roughness & Raw $S_{\text {max }}$ & -1.33 & 7.6 & 295 & 304 & 21.4 \\
\hline
\end{tabular}

Table 6: Identified parameters for Equation (4) and the fatigue strength at $2 \times 10^{6}$ cycles corresponding to each mechanism. (*: Estimated value without MLE optimisation)

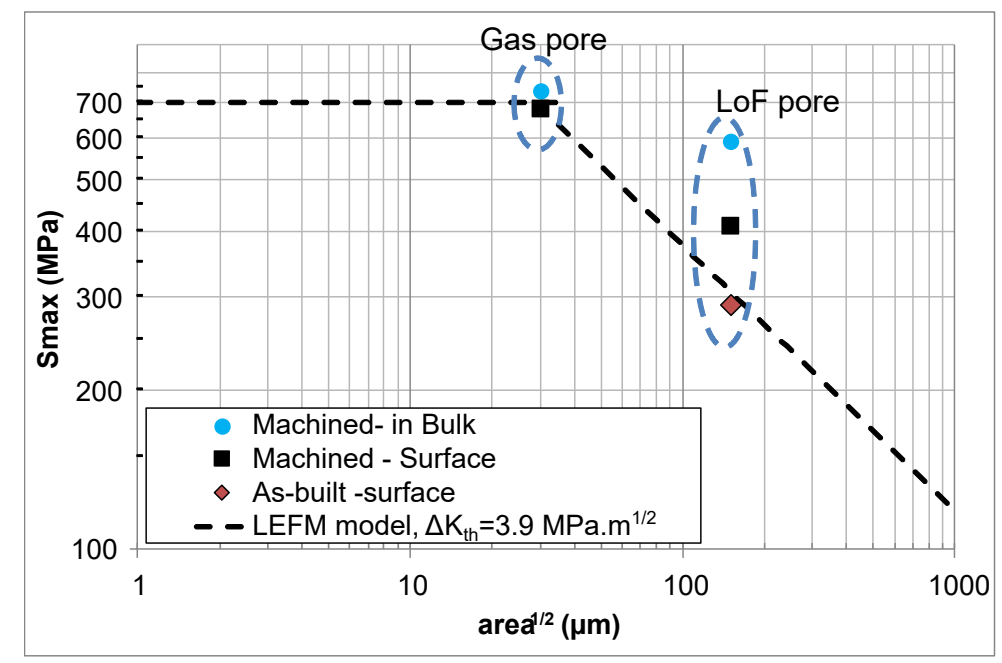

Figure 16: Kitagawa-Takahashi diagram at $\mathrm{N}_{f}=2 \times 10^{6}$ cycles

Concerning gas pores, the difference between surface and internal pores seems less pronounced. Also, the exponent identified in the S-N analysis, $s^{\prime}$, is close to zero. This implies that the effect of the gas pore size, in the range of $30 \mu \mathrm{m}$ to $50 \mu \mathrm{m}$ of $\sqrt{\text { area }}$, on the fatigue behaviour is not significant. In fact, comparison with HIPed Ti-6Al-4V alloys shows that the size of gas pores is probably located on the horizontal region of the Kitagawa-Takahashi diagram in which the pore size does not have an impact on the fatigue strength. Even though these defects can be found at the 
origin of crack initiations, their size is not large enough to significantly reduce the fatigue strength.

For the as-built specimens, it can be seen (Figure 15) again that the fatigue strength at $2 \times 10^{6}$ cycles related to the LoF pores at the surface is similar to the fatigue strength associated to the surface roughness. As mentioned earlier, in order to precisely characterise the effect of the as-built surface on the fatigue strength, the comparison between the S-N curves including only specimens with crack initiation from surface LoF pores is shown in Figure 17. Regarding the corrected S$\mathrm{N}$ curves, the same correction factors (Equation (3)) are used for the machined and the as-built specimens.

LoF pores on surface : Machined vs As-built
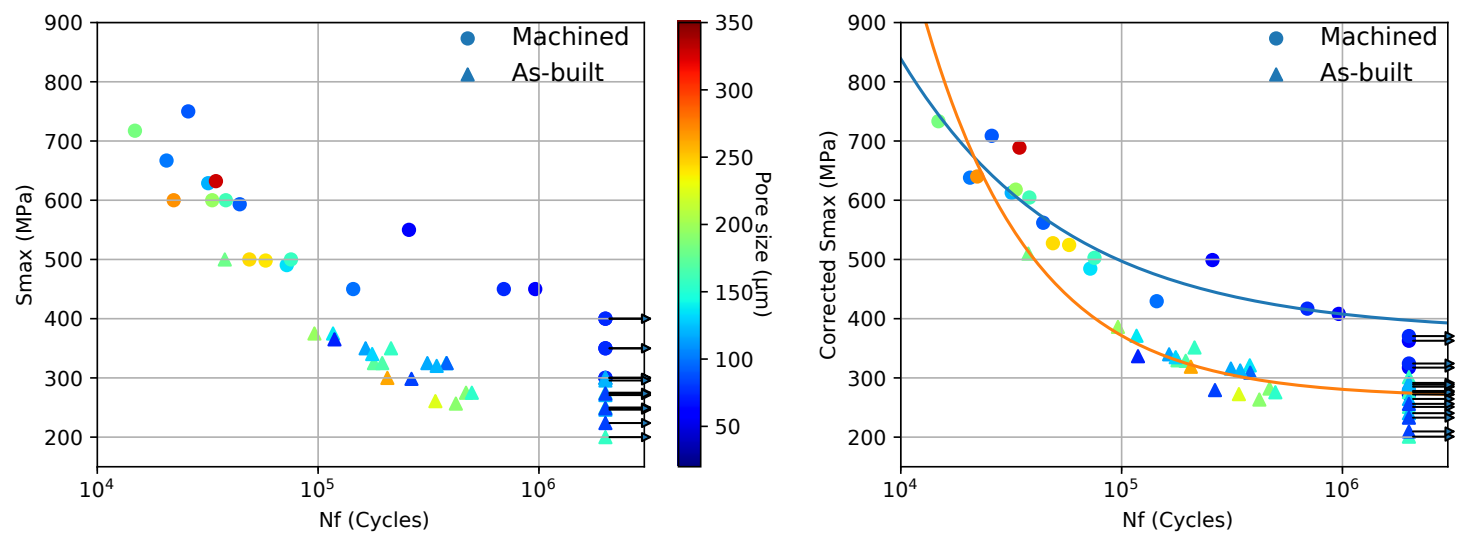

Figure 17: Uncorrected and Corrected S-N curves of machined and as-built specimens for the crack initiation mechanism related to the LoF pores on surface. Corrected Smax $=S \max \times(\sqrt{\text { area }} / 150)^{0.11}$

It can be seen that for the same critical pore size, the fatigue strength at $2 \times 10^{6}$ cycles for the as-built specimens is approximately 30\% lower than for the machined specimens (290 MPa vs $407 \mathrm{MPa}$ ). For higher stress levels with a life less than $10^{5}$ cycles, the difference attenuates. As discussed earlier, the coarse alpha lathes of the sub-surface microstructural layer (shown in Section 1.2) may be one possible explanation for this difference since it is widely known that a coarse microstructure can reduce the fatigue strength of metallic materials. Also, the higher micro-hardness of the sub-surface microstructural (Table 3) layer may be related to greater brittleness of the layer and hence, with the presence of pores, a decrease in the fatigue strength. It is also possible that the interaction between surface pores and the roughness could facilitate crack initiation from pores. In order to clearly identify the origin of the effect of the as-built surface, 
further experimental investigations should to be done.

\section{Discussion of the statistical scale/size effect}

\subsection{Origin of the size effect}

It was seen earlier in Figure 6 that, for the machined specimens, if the $\mathrm{S}-\mathrm{N}$ curves are presented without making the distinction between the different crack initiation mechanisms, the fatigue strength at $2 \times 10^{6}$ cycles of the small size specimens is higher than the standard size specimens (700 MPa vs $500 \mathrm{MPa}$ ). On the contrary, the analysis of S-N curves separately for each crack initiation mechanism in Section 3.3 showed no or very slight size effect due to the similar critical pore size distributions of the standard and small specimens, as shown in Section 2.2. Therefore, it can be concluded that the observed size effect between the standard and small specimens can not be explained by the analysis of critical pore size distributions in this work. In order to better understand the origin of the observed size effect, the probability of occurrence of each crack initiation mechanism is calculated from Table 4 and shown in Figure 18 , The total volume indicated in Figure $18 \mathrm{~b}$ corresponds to the $V_{80 \%}$ volume (i.e. the highly loaded volume in which the minimum stress is equal to the $80 \%$ of the highest stress in the whole specimen) under uniaxial tension loads.

It can be seen that for the machined specimens, the probability of occurrence of LoF pores is higher for the standard size specimens than for the small size specimens. The probability of occurrence of gas pores is greater for the small size specimens. Because the fatigue strength related to gas pore mechanisms is much higher than for the LoF pore mechanisms, it can be concluded that the size effect observed for the machined specimens is linked principally to the change of the crack initiation mechanism and not to the change of the critical pore size.

For the as-built specimens, a change of crack initiation mechanisms can also be seen in Figure 18 . The probability of occurrence of LoF pores for the standard specimens is much higher than for the small specimens, and inversely, the probability of failure from surface roughness is higher for the small specimens. However, because of the similar fatigue strengths relative to these two crack initiation mechanisms as shown in Section 3.3, the size effect is much less pronounced for as-built specimens. 


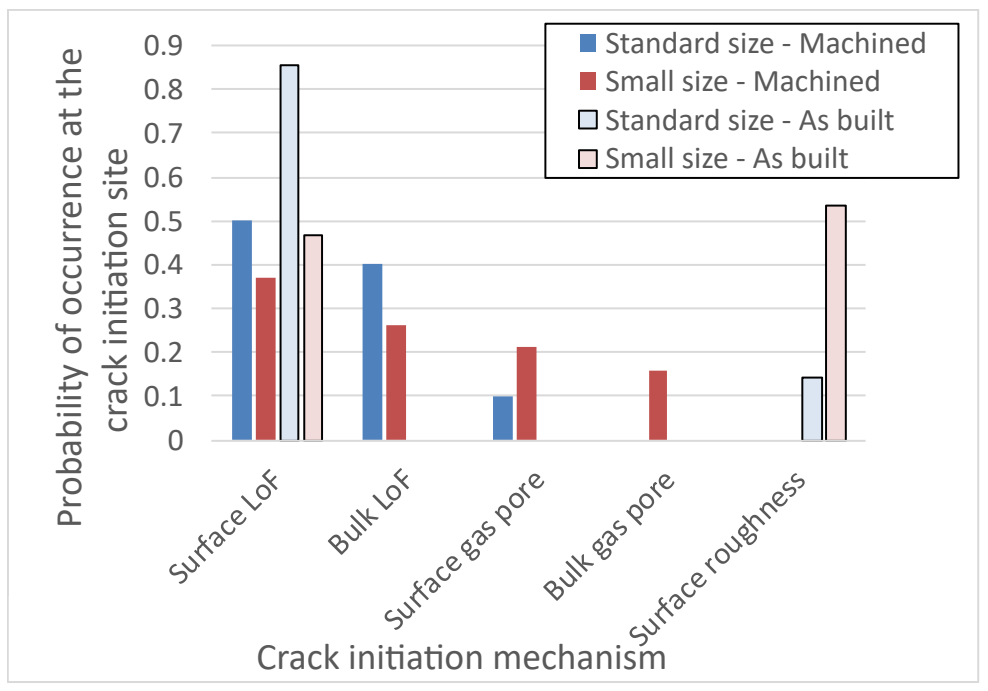

(a) Probability of occurrence of each mechanism at the crack initiation sites

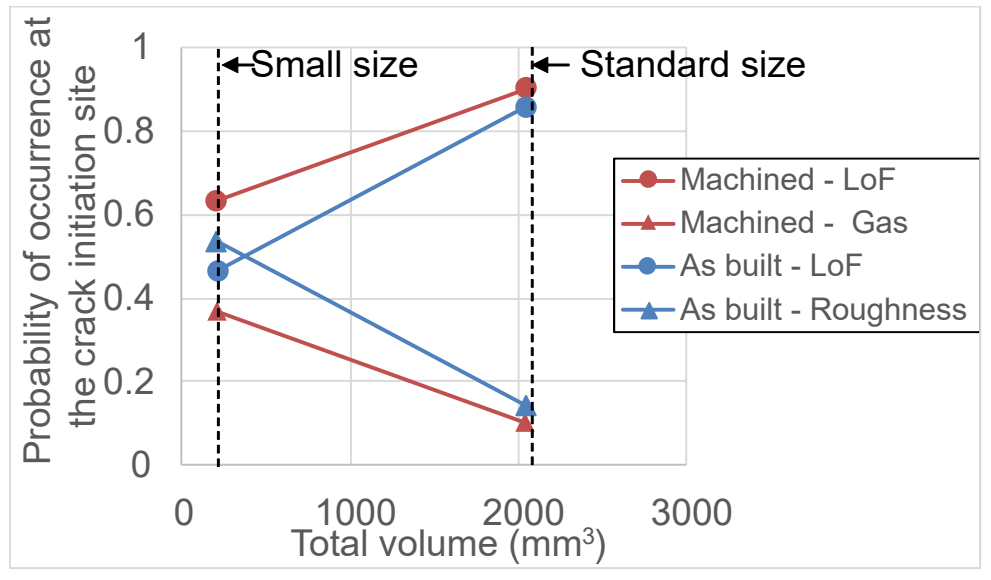

(b) Relationship between the probability of occurrence and the effective volume

Figure 18: Effect of the loaded volume on the probability of occurrence of crack initiation mechanisms

\subsection{A first step towards modelling the statistical size effect}

It was shown in the previous section that the size effect observed for machined specimens is governed principally by the change of the crack initiation mechanisms, from the LoF pore related mechanism to the gas pore related mechanism. Because the LoF pores are the most critical defects, regardless their spatial position (at the surface or in the bulk), it can be concluded the size effect observed in this work can be linked to the presence or not of the LoF pore in the loaded volume. 
The probability of fatigue failure due to a surface LoF pore is given by:

$$
P_{\text {surf }}=1-e^{-\lambda V_{\text {sub }}}
$$

If no $\mathrm{LoF}$ is present in the loaded volume, then the specimen can fail due to the gas pores. The

Whether a specimen will fail by a surface LoF pore or an internal LoF pore is decided based on the following premise: (1) if there is at least one LoF pore in volume $V$ with no LoF Pore in sub-surface volume $V_{\text {sub }}$, then the specimen fails due to the internal LoF pore; (2) If there is at least one LoF pore on surface, then the specimen fails due to the surface LoF pore.

Firstly, the probability of occurrence of crack initiation from internal LoF pores (premise (1)), $P_{\text {int }}$, is the conditional probability that one or more LoF pore will occur in volume $\mathrm{V}$ with no such defect present in $V_{\text {sub }}$ :

$$
P_{\text {int }}=\left(1-e^{-\lambda\left(V-V_{\text {sub }}\right)}\right) e^{-\lambda V_{\text {sub }}}
$$


probability of the absence of LoF in volume $V$ pore is given by:

$$
P_{n L o F}=e^{-\lambda V}
$$

Now, the loaded volume $V$ and the surface volume $V_{\text {sub }}$ must be defined. In general, crack initiation occurs in the highly loaded volume in which the minimal stress is higher than $80 \%$ of maximum stress [28, 39], or the so-called $V_{80 \%}$ volume. For the sub-surface volume, $V_{\text {sub }}$, the volume of a surface annular ring can be used, as proposed in the work of [28, 40]. The thickness of the annular sub-volume is assumed to be the maximum feret diameter of LoF pores measured on the failure surfaces (500 $\mu \mathrm{m}$ in the present work) so that all of the surface LoF pores at the crack initiation site are located entirely in the annular sub-volume.

\subsubsection{Identification of the LoF pore density}

The volumetric pore density of LoF pores, $\lambda$, is characterised by the number of pores per $\mathrm{mm}^{3}$. This pore density can be measured by X-ray micro-tomography on a sufficiently large sample sizes that has not be done in the present work. It is to note that the tomography observation shown in Figure 4 was realized on a very small sample. This observation is only for visualisation purpose but not large enough for statistical analysis. Regarding the pore densities characterised on polished samples in Section 1.2 for surface density (i.e. number of pores per $\mathrm{mm}^{2}$ ), it needs to be extrapolated to the volumetric density. Even though some extrapolation methodologies found in the literature such as the classical Murakami methodology [27] have been tried, no relevant methodology was found for the material under investigation. Hence, instead of using experimental measurements, an inverse method is used to determine the critical LoF pore density as follows.

The probabilities of occurrence of LoF pores on the surface, $P_{\text {surf }}$, of LoF pores in the bulk, $P_{\text {int }}$, or of no LoF pores in the volume, $P_{n L o F}$, are calculated for a large range of LoF pore densities. The probabilities of occurrence of critical LoF pores on the failure surfaces are then used to identify the pore density, as shown in Figure 19.

It can be seen that, by increasing the LoF pore density, the $P_{\text {surf }}$ increases while the $P_{i n t}$ and $P_{n L o F}$ decrease. By comparison with the experimental data (circular dots), i.e. the probability of occurrence at the crack initiation sites of each mechanism calculated from Table 4 , the critical LoF 


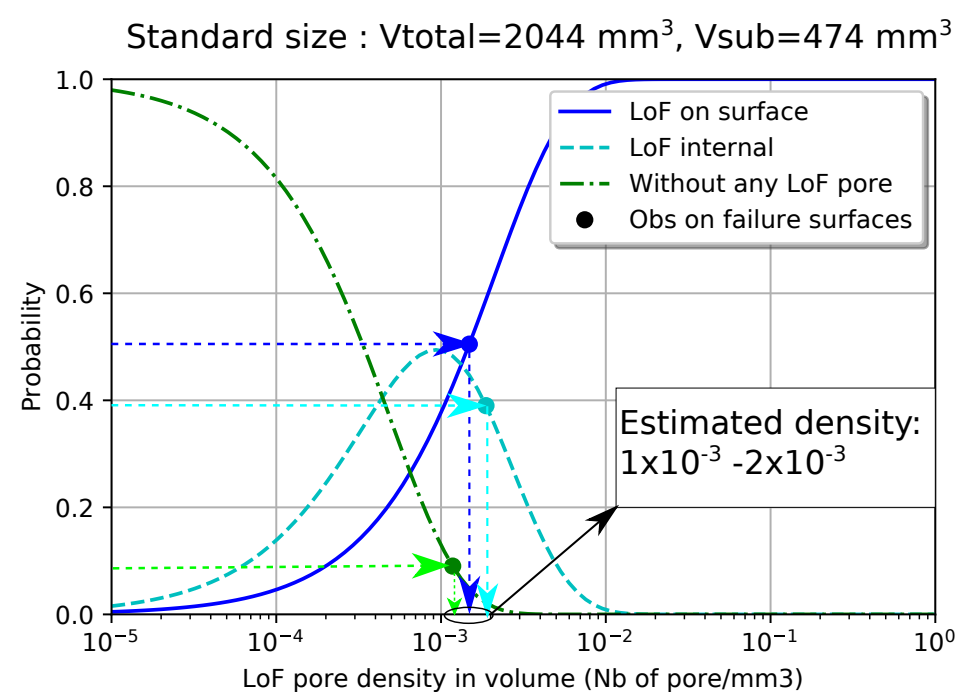

(a) Standard size specimen

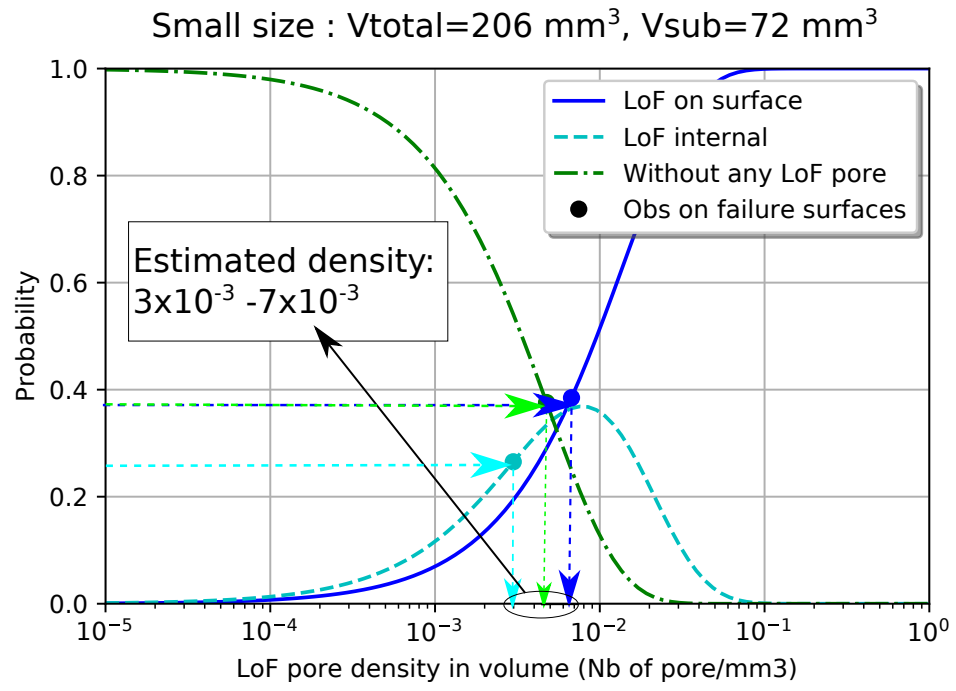

(b) Small size specimen

Figure 19: Evolution of the probabilities of occurrence of LoF pores as a function of the LoF pore density and correlation with the experimental data determined on the fatigue surfaces for (a) standard size specimens and (b) small size specimens

pore densities, $\lambda$, can be estimated to be between $1 \times 10^{-3}$ and $2 \times 10^{-3}$ pores $/ \mathrm{mm}^{3}$ for the standard size specimens. For small size specimen data, the critical LoF pore density is between $3 \times 10^{-3}$ and $7 \times 10^{-3}$ pores $/ \mathrm{mm}^{3}$. However, it must be kept in mind that this estimation does not take into account the probabilistic aspect of the experimental data due to the limited number of specimens. 


\subsubsection{Useful tools for process qualification and fatigue design}

It can be seen in Figure 19a that the maximum allowed LoF pore density is approximately $4 \times 10^{-4}$ pores $/ \mathrm{mm}^{3}$ to obtain a probability of occurrence of surface LoF pores lower than $10 \%$ for standard size specimens (with a $V_{\text {sub }}=474 \mathrm{~mm}^{3}$ ). For small size specimens (Figure $19 \mathrm{~b}$ ) with a $V_{\text {sub }}=72 \mathrm{~mm}^{3}$, the maximum allowed LoF pore density is approximately $2 \times 10^{-3}$ pores $/ \mathrm{mm}^{3}$. This way of analysis can be useful in the qualification phase of the fabrication process concerns the allowed LoF pore density to guarantee the quality of manufactured components.

Another interesting analysis is the evolution of the probability of occurrence of surface LoF pores versus the sub-surface volume shown in Figure 20 for a LoF pore density range of $1 \times 10^{-3}$ to $7 \times 10^{-3}$ pores $/ \mathrm{mm}^{3}$. It can be seen that, by increasing the volume, the occurrence probabil-

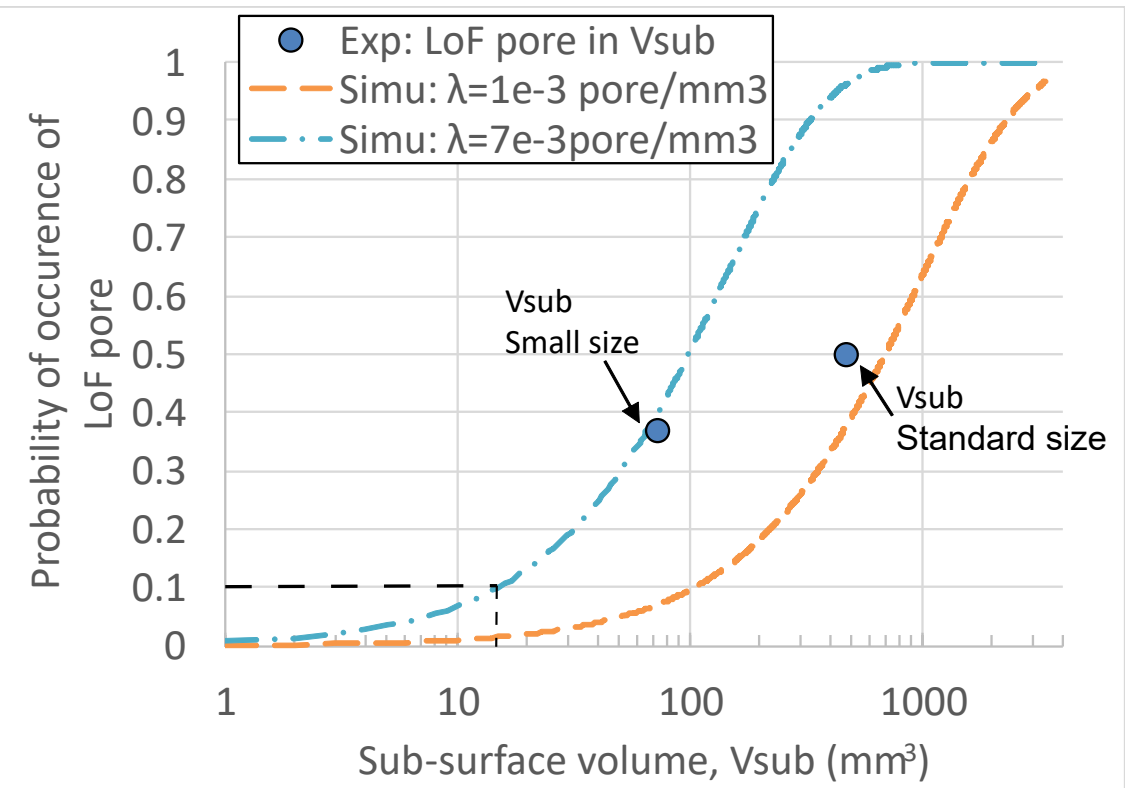

Figure 20: Correlation between the sub-surface volume and the probability of occurrence of surface LoF pores

ity of LoF pores increases rapidly. For this range of LoF pore density, the maximum size of the sub-surface volume in the loaded zone (i.e. the critical volumes) must not be greater than approximately $15 \mathrm{~mm}^{3}$ so that the probability of occurrence of surface LoF pore in this zone is lower than $10 \%$.

In short, the proposed probabilistic approach gives an effective methodology to estimate the probability of occurrence of LoF pores in a given volume. However, it must be kept in mind that 
the spatial distribution and the volumetric pore density of the LoF pores are two important inputs that must be known in this approach.

\section{Conclusion}

This paper deals with the scatter and the statistical scale/size effect of the fatigue behaviour of a SLM Ti-6Al-4V alloy. An experimental campaign was conducted on four specimen configurations with two specimen volumes (standard size and small size) and two surface conditions (as-built and machined). Numerous analyses, including an S-N curve analysis taking into account the defect size and the Kitagawa-Takahashi diagram, have been done to understand the origin of the size effect and the fatigue scatter that were observed. The principal results are as follow:

For the machined specimens:

- The presence of several fatigue crack initiation mechanisms with very different fatigue behaviours is the origin of the high scatter in the S-N data. The fatigue behaviour depends not only on the defect type (LoF pores or gas pores) but also on the spatial position of the defect (at the surface or in the bulk). The effect of the spatial position is particularly pronounced for the LoF pores. The classical Murakami approach cannot adequately predict this effect.

- The size effect observed for the machined specimens can also be explained by the variety of the crack initiation mechanisms. When analysing the mechanisms separately, only a very slight or no effect was observed because the sizes of LoF pores or the gas pores are the same for both investigated specimen volumes. The size effect is linked principally to the change of mechanism. In other words, the probability of occurrence of LoF pores and/or Gas pores in a given volume changes with a change in loaded volume.

For the as-built specimens:

- Compared to the machined specimens, the scatter in the S-N data and the size effect for the as-built specimens are greatly reduced. Despite the presence of two different crack initiation mechanisms, the similar fatigue behaviour for these mechanisms results in less scatter and and a lower size effect. 
- The fatigue behaviour related to the surface LoF pores was compared between the machined surface and the as-built surface conditions. It was shown that for a similar LoF pore size, the fatigue strength of the as-built specimens is $30 \%$ lower than that of the machined specimens. This implies that other factors, such as the sub-surface microstructure or the surface roughness may play a non-negligible role on the fatigue behaviour.

In the final part of this article, the size effect was modelled by considering the probability of occurrence of LoF pores in a given volume. The proposed model leads to useful tools that can be used in the qualification of the AM fabrication process or in the fatigue design of components.

\section{Acknowledgement}

This study is part of the FASICOM project, managed by IRT Jules Verne (French Institute of Research and Technology in Advanced Manufacturing Technologies for Composite, Metallic and Hybrid Structures). The authors wish to associate the following industrial partners with this work: ADDUP, AIRBUS, ArianeGroup and General Electric.

\section{References}

[1] E. Wycisk, A. Solbach, S. Siddique, D. Herzog, F. Walther, C. Emmelmann, Effects of defects in laser additive manufactured ti-6al-4v on fatigue properties, Physics Procedia 56 (2014) 371-378. doi:10.1016/j.phpro. 2014.08 .120

[2] J. Günther, D. Krewerth, T. Lippmann, S. Leuders, T. Tröster, A. Weidner, H. Biermann, T. Niendorf, Fatigue life of additively manufactured ti-6al-4v in the very high cycle fatigue regime, International Journal of Fatigue 94 (2017) 236-245. doi:10.1016/j.ijfatigue.2016.05.018

[3] V. Chastand, P. Quaegebeur, W. Maia, E. Charkaluk, Comparative study of fatigue properties of ti-6al-4v specimens built by electron beam melting (ebm) and selective laser melting (slm), Materials Characterization 143 (2018) 76 - 81, metal Additive Manufacturing: Microstructures and Properties. doi:https: //doi.org/10.1016/j.matchar.2018.03.028 URL http://www.sciencedirect.com/science/article/pii/S1044580317331741

[4] D. Greitemeier, F. Palm, F. Syassen, T. Melz, Fatigue performance of additive manufactured TiAl6v4 using electron and laser beam melting, International Journal of Fatigue 94 (2017) 211-217. doi:10.1016/j. ijfatigue.2016.05.001 
[5] Y. Hu, S. Wu, P. Withers, J. Zhang, H. Bao, Y. Fu, G. Kang, The effect of manufacturing defects on the fatigue life of selective laser melted ti-6al-4v structures, Materials \& Design 192 (2020) 108708. doi:10.1016/j. matdes.2020.108708

[6] R. Biswal, X. Zhang, A. K. Syed, M. Awd, J. Ding, F. Walther, S. Williams, Criticality of porosity defects on the fatigue performance of wire + arc additive manufactured titanium alloy, International Journal of Fatigue 122 (2019) 208-217. doi:10.1016/j.ijfatigue.2019.01.017

[7] A. Yadollahi, M. Mahtabi, A. Khalili, H. Doude, J. Newman, Fatigue life prediction of additively manufactured material: Effects of surface roughness, defect size, and shape, Fatigue \& Fracture of Engineering Materials \& Structures 41 (7) (2018) 1602-1614. doi:10.1111/ffe.12799

[8] B. Vayssette, N. Saintier, C. Brugger, M. E. May, E. Pessard, Numerical modelling of surface roughness effect on the fatigue behavior of ti-6al-4v obtained by additive manufacturing, International Journal of Fatigue 123 (2019) 180 - 195. doi:https://doi.org/10.1016/j.ijfatigue.2019.02.014 URL http://www .sciencedirect.com/science/article/pii/S0142112319300416

[9] K. S. Chan, M. Koike, R. L. Mason, T. Okabe, Fatigue life of titanium alloys fabricated by additive layer manufacturing techniques for dental implants, Metallurgical and Materials Transactions A 44 (2) (2012) 10101022. doi:10.1007/s11661-012-1470-4.

[10] M. H. Nasab, S. Romano, D. Gastaldi, S. Beretta, M. Vedani, Combined effect of surface anomalies and volumetric defects on fatigue assessment of alsi7mg fabricated via laser powder bed fusion Additive Manufacturing (2019) 100918doi:https://doi.org/10.1016/j.addma.2019.100918 URL http://www.sciencedirect.com/science/article/pii/S2214860419310991

[11] M. Nakatani, H. Masuo, Y. Tanaka, Y. Murakami, Effect of surface roughness on fatigue strength of ti-6al4v alloy manufactured by additive manufacturing, Procedia Structural Integrity 19 (2019) 294-301. doi:10. $1016 / j$.prostr.2019.12.032

[12] H. Masuo, Y. Tanaka, S. Morokoshi, H. Yagura, T. Uchida, Y. Yamamoto, Y. Murakami, Influence of defects, surface roughness and HIP on the fatigue strength of ti-6al-4v manufactured by additive manufacturing, International Journal of Fatigue 117 (2018) 163-179. doi:10.1016/j.ijfatigue.2018.07.020

[13] J. Pegues, M. Roach, R. S. Williamson, N. Shamsaei, Surface roughness effects on the fatigue strength of additively manufactured ti-6al-4v, International Journal of Fatigue 116 (2018) $543-552$. doi : https://doi . org $/ 10.1016 / j$.ijfatigue.2018.07.013 URL http://www.sciencedirect.com/science/article/pii/S0142112318302986

[14] A. Fatemi, R. Molaei, J. Simsiriwong, N. Sanaei, J. Pegues, B. Torries, N. Phan, N. Shamsaei, Fatigue behaviour of additive manufactured materials: An overview of some recent experimental studies on ti-6al-4v considering various processing and loading direction effects, Fatigue \& Fracture of Engineering Materials \& Structures 42 (5) (2019) 991-1009. arXiv:https://onlinelibrary.wiley.com/doi/pdf/10.1111/ffe.13000, doi:10. 
$1111 /$ ffe. 13000

URL https://onlinelibrary.wiley.com/doi/abs/10.1111/ffe.13000

[15] V.-D. Le, E. Pessard, F. Morel, F. Edy, Interpretation of the fatigue anisotropy of additively manufactured ta6v alloys via a fracture mechanics approach. Engineering Fracture Mechanics 214 (2019) 410 - 426. doi: https: //doi.org/10.1016/j.engfracmech.2019.03.048. URL http://www.sciencedirect.com/science/article/pii/S0013794418311664

[16] A. International, ASTM F3001-14, Standard Specification for Additive Manufacturing Titanium-6 Aluminum-4 Vanadium ELI (Extra Low Interstitial) with Powder Bed FusionCited By 5.

[17] L. Thijs, F. Verhaeghe, T. Craeghs, J. V. Humbeeck, J.-P. Kruth, A study of the microstructural evolution during selective laser melting of ti-6al-4v, Acta Materialia 58 (9) (2010) 3303-3312. doi:10.1016/j.actamat. 2010.02 .004

[18] G. Kasperovich, J. Hausmann, Improvement of fatigue resistance and ductility of TiAl6v4 processed by selective laser melting, Journal of Materials Processing Technology 220 (2015) 202-214. doi:10.1016/j. jmatprotec.2015.01.025

[19] R. D. Pollak, A. N. Palazotto, A comparison of maximum likelihood models for fatigue strength characterization in materials exhibiting a fatigue limit, Probabilistic Engineering Mechanics 24 (2) (2009) 236 - 241. doi: https://doi.org/10.1016/j.probengmech.2008.06.006.

URL http://www.sciencedirect.com/science/article/pii/S026689200800057X

[20] M. Donachie, Titanium: a technical guide, ASM International, 2000. URL https://books.google.fr/books?id=IJFUAAAAMAAJ

[21] H. Gong, K. Rafi, T. Starr, B. Stucker, Effect of defects on fatigue tests of as-built ti-6al-4v parts fabricated by selective laser melting, in: 23rd Annual International Solid Freeform Fabrication Symposium - An Additive Manufacturing Conference, SFF 2012, 2012.

[22] H. K. Rafi, T. L. Starr, B. E. Stucker, A comparison of the tensile, fatigue, and fracture behavior of ti-6al-4v and 15-5 PH stainless steel parts made by selective laser melting, The International Journal of Advanced Manufacturing Technology 69 (5-8) (2013) 1299-1309. doi:10.1007/s00170-013-5106-7.

[23] K. Walker, Q. Liu, M. Brandt, Evaluation of fatigue crack propagation behaviour in ti-6al-4v manufactured by selective laser melting, International Journal of Fatigue 104 (2017) 302 - 308. doi:https://doi.org/10. $1016 / j$.ijfatigue.2017.07.014 URL http://www.sciencedirect.com/science/article/pii/S0142112317303043

[24] B. Gerin, E. Pessard, F. Morel, C. Verdu, A non-local approach to model the combined effects of forging defects and shot-peening on the fatigue strength of a pearlitic steel, Theoretical and Applied Fracture Mechanics 93 (2018) 19 - 32. doi:https://doi.org/10.1016/j.tafmec.2017.06.012 URL http://www.sciencedirect.com/science/article/pii/S0167844217301209 
[25] S. Pomberger, M. Stoschka, R. Aigner, M. Leitner, R. Ehart, Areal fatigue strength assessment of cast aluminium surface layers, International Journal of Fatigue 133 (2020) 105423. doi:10.1016/j.ijfatigue. 2019.105423

[26] E. Gumbel, Statistical theory of extreme values and some practical applications: a series of lectures, Applied mathematics series, U. S. Govt. Print. Office, 1954.

URL http://books.google.fr/books?id=SNpJAAAAMAAJ

[27] Y. Murakami, Effects of small defects and nonmetallic inclusions, Elsevier, 2002.

[28] D. E. Khoukhi, F. Morel, N. Saintier, D. Bellett, P. Osmond, V.-D. Le, J. Adrien, Experimental investigation of the size effect in high cycle fatigue: Role of the defect population in cast aluminium alloys, International Journal of Fatigue 129 (2019) 105222. doi:https://doi.org/10.1016/j.ijfatigue.2019.105222 URL http://www.sciencedirect.com/science/article/pii/S0142112319303263

[29] R. Molaei, A. Fatemi, N. Sanaei, J. Pegues, N. Shamsaei, S. Shao, P. Li, D. Warner, N. Phan, Fatigue of additive manufactured ti-6al-4v, part II: The relationship between microstructure, material cyclic properties, and component performance, International Journal of Fatigue 132 (2020) 105363. doi:10.1016/j.ijfatigue. 2019.105363

[30] M.J.Caton, J.W.Jones, H.Mayer, S. Stanzl-Tschegg, J.E.Allison, Demonstration of an endurance limit in cast 319 aluminum, Metallurgical and Materials Transactions A 34 (11) (2003) 33-41.

[31] N. Hrabe, T. Gnäupel-Herold, T. Quinn, Fatigue properties of a titanium alloy (ti6al4v) fabricated via electron beam melting (ebm): Effects of internal defects and residual stress, International Journal of Fatigue 94 (2017) 202 - 210, fatigue and Fracture Behavior of Additive Manufactured Parts. doi:https://doi .org/10.1016/ j.ijfatigue.2016.04.022

URL http://www.sciencedirect.com/science/article/pii/S0142112316300767

[32] X. Shui, K. Yamanaka, M. Mori, Y. Nagata, K. Kurita, A. Chiba, Effects of post-processing on cyclic fatigue response of a titanium alloy additively manufactured by electron beam melting, Materials Science and Engineering: A 680 (2017) 239-248. doi:10.1016/j.msea.2016.10.059

[33] S. Leuders, T. Lieneke, S. Lammers, T. Tröster, T. Niendorf, On the fatigue properties of metals manufactured by selective laser melting - the role of ductility, Journal of Materials Research 29 (17) (2014) 1911-1919. doi:10.1557/jmr.2014.157.

[34] Y. Murakami, S. Beretta, Small defects and inhomogeneities in fatigue strength: Experiments, models and statistical implications Extremes 2 (2) (1999) 123-147. doi:10.1023/A:1009976418553. URL https : //doi .org/10.1023/A :1009976418553

[35] O. Andreau, E. Pessard, I. Koutiri, J.-D. Penot, C. Dupuy, N. Saintier, P. Peyre, A competition between the contour and hatching zones on the high cycle fatigue behaviour of a 3161 stainless steel: Analyzed using X-ray computed tomography, Materials Science and Engineering: A 757 (2019) 146 - 159. doi:https://doi.org/ 
10.1016/j.msea.2019.04.101

URL http://www.sciencedirect.com/science/article/pii/S0921509319305763

[36] A. Junet, A. Messager, X. Boulnat, A. Weck, E. Boller, L. Helfen, J.-Y. Buffiere, Fabrication of artificial defects to study internal fatigue crack propagation in metals, Scripta Materialia 171 (2019) 87-91. doi:10.1016/j. scriptamat.2019.05.018.

[37] I. Serrano-Munoz, J.-Y. Buffiere, C. Verdu, Y. Gaillard, P. Mu, Y. Nadot, Influence of surface and internal casting defects on the fatigue behaviour of a357-t6 cast aluminium alloy, International Journal of Fatigue 82,

Part 3 (2016) 361 - 370. doi:http://dx.doi.org/10.1016/j.ijfatigue.2015.07.032 URL http://www.sciencedirect.com/science/article/pii/S0142112315002509

[38] K. S. R. Chandran, Duality of fatigue failures of materials caused by poisson defect statistics of competing failure modes, Nature Materials 4 (4) (2005) 303-308. doi:10.1038/nmat1351

[39] P. Osmond, V.-D. Le, F. Morel, D. Bellett, N. Saintier, Effect of porosity on the fatigue strength of cast aluminium alloys: from the specimen to the structure, Procedia Engineering 213 (2018) 630-643. doi: $10.1016 / j \cdot$ proeng.2018.02.059

[40] V.-D. Le, N. Saintier, F. Morel, D. Bellett, P. Osmond, Investigation of the effect of porosity on the high cycle fatigue behaviour of cast al-si alloy by x-ray micro-tomography, International Journal of Fatigue 106 (2018) 24-37. doi:10.1016/j.ijfatigue.2017.09.012 